\title{
GENETIC AND DEMOGRAPHIC FACTORS OF A BRAZILIAN POPULATION SAMPLE AT-RISK OF HEREDITARY BREAST AND OVARIAN CANCER
} Fatores genéticos e demográficos de uma amostra da população brasileira sob risco de síndrome de câncer de mama e ovário hereditários

Guilherme Olivetti Guarneri', Bruno Jerônimo Ponte1', João Henrique Fregadolli Ferreira', Leonardo Kenji Nesi Mitsutake ${ }^{1}$, Murilo Henrique Guedes ${ }^{1}$, José Cláudio Casali-da-Rocha*

\section{ABSTRACT}

Objective: Genetic-related breast cancer has a tendency to manifest earlier and to be more aggressive than sporadic cancer. There are few studies evaluating the prevalence and incidence of hereditary breast and ovarian cancer (HBOC) among Brazilians. In order to improve assistance, efforts to characterize the population at risk of HBOC could help to formulate locally designed guidelines. Methodology: Descriptive retrospective study in Hospital Erasto Gaertner's service of Oncogenetics, in Curitiba, state of Paraná, Brazil. We included individuals at-risk for HBOC, according to the National Comprehensive Cancer Network (NCCN) criteria, who had performed genetic tests for HBOC. We collected complete family history, presented as heredograms. We excluded families with inappropriate family history. Results: Of the 27 patients analyzed (total of 25 families), $7 \%$ were asymptomatic, $8 \%$ had ovarian cancer and $85 \%$ had breast cancer. Mutations were found in $29.6 \%, 6$ cases of BRCA1, 1 of BRCA2 and 1 of TP53. Triple negative was the most common reported subtype, representing $60 \%$ of breast cancers; among patients with identified pathogenic variants, 2 were BRCA2 mutated and 1 TP53 mutated. The mean age of diagnosis was 40 years for those identified as probands on heredograms; in the generation above, it was 52,5, and in the below, 33, suggesting the antecipation phenomena Two new mutations were identified in Brazilian population, both in BRCA1: c.4258 G>A and c.5345 G>A. The most frequent NCCN criteria were number 2, 9, 8 and 4. Estimated penetrance was 22\%. Conclusion: This is the first descriptive study in the population at-risk for $\mathrm{HBOC}$ in the state of Paraná. We could identify two new pathogenic variants of BRCA1 in Brazilian population. A comprehensive family history was included in the study, depicted as heredograms of each family. Despite the low number of patients, the main results are in agreement with previous studies.

KEYWORDS: breast cancer; HBOC syndrome; BRCA1 gene; BRCA2 gene.

${ }^{1}$ Hospital Erasto Gaertner - Curitiba (PR), Brazil.

*Corresponding author: casalidarocha@gmail.com

Conflict of interests: nothing to declare.

Received on: 02/27/2018. Accepted on: 07/14/2018 


\section{RESUMO}

Objetivo: Os carcinomas de mama hereditários têm a tendência de se manifestar precocemente e serem mais agressivos do que os esporádicos. São poucos os estudos que avaliam a prevalência e a incidência da síndrome de câncer de mama e ovário hereditário $(\mathrm{SCMOH})$ na população brasileira. No intuito de melhorar a assistência prestada, a análise das características encontradas na população em risco para SCMOH ajudaria a formulação de protocolos regionais para a abordagem desses pacientes. Metodologia: Estudo descritivo retrospectivo realizado no serviço de Oncogenética do Hospital Erasto Gaertner em Curitiba, Paraná. Incluímos indivíduos em risco para SCMOH pelos critérios estabelecidos pela National Comprehensive Cancer Network (NCCN) e que realizaram testes genéticos para SCMOH. Coletamos o histórico familiar completo, apresentado na forma de heredograma. Foram excluídas famílias com histórico familiar inapropriado. Resultados: Das 27 pacientes analisadas (total de 25 famílias), 7\% eram assintomáticas, 8\% tiveram câncer de ovário e 85\%, câncer de mama. Mutações foram encontradas em 29,6\%, sendo 6 casos de BRCA1, 1 de BRCA2 e 1 de TP53. Tumores triplo negativos foram os mais encontrados entre os subtipos, representando $60 \%$ dos carcinomas de mama; dentre os pacientes com variantes patogênicas, 2 eram de mutações em $B R C A 2$ e 1 em TP53. A média de idade entre as pacientes foi de 40 anos entre probandas dos heredogramas; na geração superior, foi de 52,5 anos e na inferior, de 33, sugerindo o fenômeno de antecipação. Duas novas mutações foram descritas na população brasileira, as duas sendo em BRCA1: c.4258 G>A e c.5345 G>A. Os critérios NCCN mais encontrados foram os de número 2, 9, 8 e 4. A penetrância estimada foi de 22\%. Conclusão: Este foi o primeiro estudo descritivo de uma população em risco para SCMOH no estado do Paraná. Encontramos duas novas mutações que não haviam sido descritas na população brasileira até então. Foi realizada a análise detalhada do histórico familiar das pacientes, sendo descrita e detalhada em heredogramas para cada família. Apesar do baixo número de indivíduos analisados, os resultados principais foram de acordo com o encontrado em estudos prévios.

PALAVRAS-CHAVE: câncer de mama; síndrome de câncer de mama e ovário hereditário; genes BRCA1; genes BRCA2.

\section{INTRODUCTION}

The real determinants for the development of breast cancer have not yet been established and its emergence is associated to the interaction of multiple factors, be they environmental/behavioral, are related to the reproductive/hormonal history, being either genetic/hereditary. Advanced age, female gender, exposure to the estrogen hormone, obesity - mainly after menopause and the presence of mutations in genes called tumor suppressors are some of these factors ${ }^{1}$. These hereditary tumors have a clear tendency to manifest earlier and with more aggressive progression - represented by tumors of the triple negative type ${ }^{2}$.

Although most breast cancers are associated with sporadic mutations, about 5 to $10 \%$ of them have hereditary ones. Clinically, the so-called hereditary breast and ovarian cancer (HBOC) syndrome is characterized by early manifestation of breast neoplasm or other primary sites such as ovary, prostate, and pancreas associated with family history of neoplasms at these sites. More than $90 \%$ of the cases of this syndrome have mutations in BRCA1 or BRCA2 genes; less commonly, mutations are observed in the PTEN, TP53 and STK11 genes, associated, respectively, with the Cowden, Li-Fraumeni and Peutz-Jeghers syndromes ${ }^{2,3}$.

The BRCA1 and BRCA2 genes, located on chromosomes 17q21 and 13q12.3, respectively, encode proteins involved in the repair of DNA double-strand breaks, thus having an important role in the regulation of the cell cycle. From the point of view of carcinogenesis, these genes are considered tumor suppressors and, when mutated, lead to changes that predispose to the development of the neoplasia. Hundreds of mutations have been described in both genes and their prevalence and penetrance are influenced by the study population. Frequency is thought to be rare in most populations - occurring in approximately 1 in 400 people $^{3}$.

In addition, some of these mutations may be highly penetrating; a 2007 meta-analysis estimated the cumulative risk for the development of breast and ovarian cancer by the age of 70 years: 57 and $40 \%$ for mutation in the BRCA1 gene and 49 and $18 \%$ for BRCA 24 . In this context, the identification of individuals with these mutations became the object of study and genetic counseling, a tool for evaluation and communication of personal and family risks, screening and early diagnosis/treatment.

The National Comprehensive Cancer Network (NCCN) has formulated the guideline that establishes the criteria for genetic research of $\mathrm{HBOC}$, favoring access for the research of potential mutation carriers and the use of genetic tests for the family. A mapping of the family tree of the family and analysis of the family history of cancers is necessary for this diagnosis. The present study consists of a complete analysis of the demographic and genetic profile of families that meet $\mathrm{HBOC}$ criteria according to the NCCN, correlating them with the main preventive, diagnostic and therapeutic measures.

\section{METHODS}

This is a retrospective descriptive study performed in patients attended at the Oncogenetics Service of Hospital Erasto Gaertner 
(HEG) with diagnosis or suspicion of HBOC by the NCCN criterion v1.2017 (Table 1) $)^{5}$ attended in the period from 2012 to 2015. Patients included were those at high risk (according to NCCN), tested for mutations in BRCA1 or BRCA2 genes, diagnosed with tumor (benign or malignant) or asymptomatic.

Table 1. National Comprehensive Cancer Network criteria modified for genetic research.

1. Family history with known deleterious mutation of BRCA1 / BRCA2;

2. Personal history of breast cancer + diagnosis with $\leq 45$ years;

3. Personal history of breast cancer + diagnosis at $\leq 50$ years + history of another primary breast cancer ${ }^{1}$;

4. Personal history of breast cancer + diagnosis with $\leq 50$ years + Family history ${ }^{2}$ with breast cancer at any age;

5. History of other breast cancer + diagnosis at $\leq 50$ years + Family history of pancreatic cancer;

6. Personal history of breast cancer + diagnosis at $\leq 50$ years + Family history of prostate cancer (Gleason $\geq 7$ );

7. Personal history of breast cancer + Diagnosis with $\leq 50$ years + Limited or unknown family history;

8. Personal history of breast cancer + Diagnosis with $\leq 60$ years with triple negative cancer;

9. Personal history of breast cancer + Diagnosis at any age + Family history of breast cancer aged $\leq 50$ years;

10. Personal history of breast cancer + Diagnosis at any age + two or more relatives with breast cancer at any age:

11. Personal history of breast cancer + Diagnosis at any age + Family history of invasive ovarian cancer $^{3}$;

12. Personal history of breast cancer + Diagnosis at any age + two or more relatives with cancer of the pancreas or prostate (Gleason $\geq 7$ ) at any age;

13. Personal history of breast cancer + Diagnosis at any age + Family history of male breast cancer;

14. Personal history of breast cancer + Diagnosis at any age + Ashkenazi family ancestry*;

15. Personal history of invasive ovarian cancer;

16. Personal history of male breast cancer;

17. Personal history of prostate cancer (Gleason $\geq 7$ ) at any age + Family history of breast cancer ( $\leq 50$ years) and/or invasive ovary, pancreas or prostate cancer (Gleason $\geq 7$ ) at any age;

18. Personal history of pancreatic cancer at any age + Family history of breast cancer ( $\leq 50$ years), invasive ovary or pancreas at any age;

19. Personal history of pancreatic cancer + Ashkenazi ancestry*;

20. Family history of 1st or 2 nd degree that fulfills the criteria above;

21. Family history of 3rd grade with invasive breast or ovarian cancer with two or more relatives diagnosed with breast cancer ( $\leq 50$ years).

${ }^{1}$ Two cases of primary breast CA include bilateral contralateral frames, in addition to two or more ipsilateral primary tumors, clearly separated, being both synchronous and non-synchronous; ${ }^{2}$ families include first, second, and third-degree relatives on the same side of the family; ${ }^{3 i n c l u d e ~ c a r c i n o m a s ~ o f ~ t h e ~ u t e r i n e ~ f a l l o p i a n ~ t u b e s ~ a n d ~ p r i m a r y ~}$ peritoneum * *Genetic testing to prove descent should be performed.
The inclusion criteria are shown in Table 1 and were modified to allow the quantification of the number of criteria per family in a systematic way. Among the exclusion criteria are: patients not tested for BRCA1 and BRCA2 gene mutations, with medical records without test information or patients without a heredogram.

Demographic variables (age, gender), clinical ones related to the individual (family history including heredogram, risk factors, staging), pathological variables related to the tumor (histology, pathological staging, degree, immunohistochemical profile, multicentrality and multiplicity) and genetic variables (results of diagnostic and predictive genetic tests) were collected.

The heredograms were scanned using the Genial Pedigree Draw software, available online at www.pedigreedraw.com. The information contained in the heredograms was reviewed by more than one author for confirmation of the data. The captions were standardized in a consensual way between the authors, discarding information of non-neoplastic diseases or diseases not related to the genetic syndromes of the study in question. Each family has been individually described and its respective heredogram is attached to the end of the work.

The data were tabulated in worksheets of Microsoft Excel and later analyzed descriptively in relation to:

- mean age at diagnosis of breast cancer;

- proportion of the sample to specific NCCN criteria;

- molecular classification of breast cancer (expression of estrogen receptors, progesterone by immunohistochemistry and HER-2 by immunohistochemistry/FISH);

- prevalence of histological subtypes and clinical stage at diagnosis;

- prevalence of primary tumors at multiple sites;

- phenotypes: prevalence of neoplasms in families, anticipation phenomenon (difference in mean age of presentation of neoplasia in different generations) and penetrance (proportion of patients with mutation that expressed the breast and/or ovary cancer phenotype).

\section{RESULTS}

Twenty-five families were evaluated in the period from 2013 to 2015 for inclusion in this study. Table 1 shows the process of selection of the patients eligible for the present study, based on the NCCN criteria, totaling 27 patients who were probands for the study.

The general characteristics of the population are described in Table 2. All the sample included were women, with ages varying from 27 to 68 years, all tested for mutations in BRCA1 and BRCA2 genes. Significant mutations were identified in six patients $(22 \%)$ in the BRCA1 gene, one in the BRCA2 gene (3.7\%) and one in the TP53 gene (3.7\%). Of the 27 patients, 25 had been diagnosed with some kind of neoplasia. Of these, most had breast cancer (92\%), mean age at diagnosis of 42 years in the general population, 
50 years in patients whose tests detected mutations and 39 years in which no mutation had been detected.

Regarding the molecular classification of breast cancer - as shown in Graphic 1 -, 47.8\% of the sample presented neoplasms whose expression profiles were negative for estrogen, progesterone and HER-2 receptors, being classified, thus, as carriers of triple negative breast cancer. Among the patients with defined genetic diagnosis, the triple negative subtype was identified in $60 \%$ of the carriers of mammary neoplasia. The luminal subtypes A, B and HER-2 constituted, respectively, 30, 13 and 8.6\% of the overall sample.

All families had their heredograms scanned and analyzed. Of these, six (24\%) presented only breast cancer in the family history, while the other $19(76 \%)$ presented other neoplasms, besides the breast one. Four families (16\%) had cases of both breast and ovarian cancer. The occurrence in the same family of breast and gastrointestinal or breast cancer and haematological neoplasia was, respectively, eight (32\%) and six (24\%) cases. Other associations between breast cancer and neoplasms in other sites were less frequent: five cases (20\%) of the prostate, four (16\%) of the central nervous system, four (16\%) of the head and neck, four (16\%) of lung, and three (12\%) colorectal. There was no association between breast and pancreatic cancer or cases of male breast cancer.

Table 2. General characteristics of the population.

\begin{tabular}{l|c|c|c}
\hline Total patients & $\begin{array}{c}\text { General } \\
\text { population }\end{array}$ & $\begin{array}{c}\text { Mutation } \\
\text { detected }(\%)\end{array}$ & $\begin{array}{c}\text { Mutation not } \\
\text { detected (\%) }\end{array}$ \\
\hline $\begin{array}{l}\text { Total cancer } \\
\text { patients }\end{array}$ & 27 & $8(29.6 \%)$ & $19(70.4 \%)$ \\
\hline Ovarian cancer & 2 & $2(100.0 \%)$ & 0 \\
\hline Breast cancer & 23 & $5(20.0 \%)$ & $18(80.0 \%)$ \\
\hline Luminal A & 7 & $1(14.3 \%)$ & $6(85.7 \%)$ \\
\hline Luminal B & 3 & $1(33.0 \%)$ & $2(66.7 \%)$ \\
\hline Basal & 11 & $3(27.0 \%)$ & $8(73.0 \%)$ \\
\hline HER-2 & 2 & 0 & $2(100.0 \%)$ \\
\hline $\begin{array}{l}\text { Mean age at } \\
\text { diagnosis * }\end{array}$ & 42 & 50 & 39 \\
\hline
\end{tabular}

* Breast and ovarian considered together; SD: standard deviation.

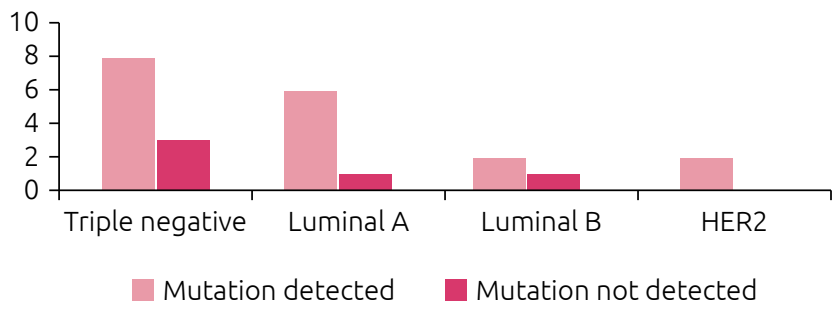

Graphic 1. Pathological characteristics $\times$ genetic
On average, the generation to which the proband belonged had three cases of breast cancer and a standard deviation of 3.4, with a mean age at diagnosis of approximately 40 years among the carriers. The estimated mean penetrance was $22 \%$ with a standard deviation of $15 \%$ in the sample. Considering the probands whose maternal or paternal generations separately presented cases of breast cancer, the estimated difference between the means of age at the diagnosis of breast neoplasm was 12.5 years between the superior generation and the proband. For the occurrences in which the generation below the proband presented cases of breast cancer, the difference between the means of age at diagnosis was of seven years, as described in Table 3 .

Regarding the distribution of the NCCN criteria for hereditary breast and ovarian cancer syndrome, described in Graphic 2, parameters 2, 9 and 11 were highlighted, so that they were positive in approximately 68,48 and $44 \%$ of the sample, respectively . In addition, criteria 4 and 10 were present in a good part of the patients included, the first one being at $40 \%$ and the second at $36 \%$, whereas parameters $1,7,11,20$ and 21 were identified in 8 , $12,16,16$ and $4 \%$ of the patients, in that order.

Regarding the disposition of the mutations per family (Table 4), it was observed that in the 6 the mutation c.5345G>A:p.Trp1782Ter nonsense type in the BRCA1 gene was detected; in turn, the 10 had the p.R337H (c.1010G>A:p.Arg337His) mutation, nonsense type, sequenced in the TP53 gene; the 22 presented a duplication of the exon 20 of the BRCA1 gene, a frameshift-like mutation, still

Table 3. Penetrance and anticipation data.

\begin{tabular}{l|c|c}
$\begin{array}{l}\text { Number of cases of breast cancer in the } \\
\text { generation of the proband }\end{array}$ & 3 & 3.4 \\
\hline $\begin{array}{l}\text { Cases of breast cancer/total of } \\
\text { individuals in the generation }\end{array}$ & $22 \%$ & $15 \%$ \\
\hline Age at diagnosis — first generation * & 52.5 & 11.4 \\
\hline Age at diagnosis — second generation * & 40 & 8.2 \\
\hline Age at diagnosis — third generation * & 33 & 8.4 \\
\hline * The second generation was considered to be the proband's.
\end{tabular}

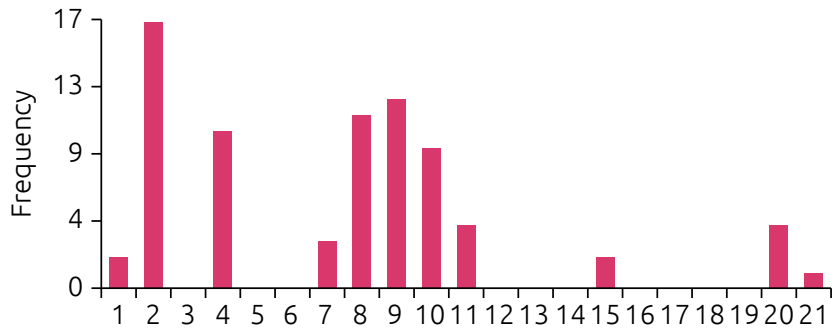

Graphic 2. Frequency of National Comprehensive Cancer Network criteria. 
without data in the bases evaluated ${ }^{6}$; the 23 presented the mutation c.4258C> T (p.Gln1420Ter) nonsense type in the BRCA1 gene; the c.5266dupC:p.Gln1756Profs mutation, frameshift type, in the BRCA1 gene was detected at 24; and 25 showed the nonsense c.6405_6408delCTTA mutation in the BRCA2 gene.

\section{Description of the families}

Each of the families described has its own heredogram, attached to the end of the article.

\section{Family 1}

The proband of family 1 presented breast cancer at 32 years of age and no other tumor. The molecular presentation of their tumor is expressed as $70 \% \mathrm{Ki} 67$ and triple negative. Their clinical diagnosis was of a multicentric right breast tumor. As NCCN criteria, it presented the numbers 2, 4, 8 and 9. The BRCA1, BRCA2, TP53 and CHEK2 genes were tested: no mutations were found in the TP53 and CHEK2 genes; in BRCA1 and BRCA2, variants without clinical significance were found.

Their heredogram reveals a breast neoplasm in a cousin from their maternal side, whose diagnosis occurred at age 26, and prostate cancer in the maternal grandfather. We highlight the absence of neoplasias in the generation above the proband, composed of 12 women and 4 men.

\section{Family 2}

The proband of family 2 had a diagnosis of breast cancer at age 33, an invasive mammary carcinoma of the triple negative type. They did not present another tumor. The BRCA1 gene was sequenced and no pathogenic mutations were found.

To the heredogram, we found the mother with ovarian cancer at age 47 and two other maternal aunts with breast cancer, both diagnosed at age 30 - one of these maternal aunts is the paternal grandmother of a cancer carrier with no known site at 20 years of age. It is worth mentioning the presence of two sisters and six nieces of the proband with no tumor history.

\section{Family 3}

The family 3 proband had a diagnosis of luminal B invasive breast cancer at age 37, this being their only cancer. Its tumor expresses
$10 \%$ of Ki67 and HER-2 (FISH). Genetic tests were performed on the BRCA1 and BRCA2 genes, and no clinically relevant mutations were found. Of the NCCN criteria, the proband presented the ones of numbers 2,4 and 9.

In the heredogram, we found a positive history on the paternal side: the grandmother was diagnosed with breast cancer at age 50. Two sisters of the father have a negative history for the neoplasia, as well as the sister and brother of the analyzed subject.

\section{Family 4}

Family 4 has a proband with diagnosis of ductolobular carcinoma of the breast at age 45, their only tumor. Their neoplasm is triple negative. The BRCA1, BRCA2, TP53 and CHEK2 genes were tested, and no clinically significant variations were found. They meet NCCN criteria 2, 4, 8 and 9.

Heredogram shows the mother with breast cancer (diagnosis at age 48) and one of the five sisters of the mother has a history of non-melanoma skin cancer; In addition, the maternal grandfather had melanoma at age 54, the father of their maternal grandfather had prostate cancer at age 82 and their siblings had prostate (60 years), skin (69 years) and gastrointestinal (72 years) tumors. We highlight the presence of only one case of mammary carcinoma among the six female members of the generation above the proband, in addition to the limited family history, since proband is the only woman of her generation.

\section{Family 5}

Family 5 has a proband whose invasive ductal carcinoma of the breast was diagnosed at 39 years of age, being the only cancer. The tumor has $30 \% \mathrm{Ki}-67$ expression and is triple negative. The NCCN criteria met were those of number 2, 4 and 8. Their genetic test was performed for BRCA1 and the result was negative.

In the heredogram, on one side of the family, we found a positive history of prostate cancer in the maternal uncle, diagnosed at age 38, a grandfather with gastrointestinal cancer and a maternal great grandmother with bilateral breast cancer, the latter being diagnosed at age 112; on the other side of the family, a paternal aunt presented breast cancer at age 63 and a paternal cousin had head/neck cancer at 41 . It is noteworthy that,

Table 4. Sample mutations ${ }^{6}$

\begin{tabular}{l|c|c|c|c|c} 
Family & Gene/Transcript & Variant & Classification & Consequence & dbSNP \\
6 & BRCA1_NM_007294.3 & c.5345G>A (p.Trp1782Ter) & Pathogenic & Nonsense & rs80357219 \\
\hline 10 & TP53_NM_000546.5 & c.1010G>A (p.Arg337His) & Pathogenic & Missense & rs121912664 \\
\hline 22 & BRCA1_NM_007294.3 & Duplication exon 20* & Pathogenic & * & $*$ \\
\hline 23 & BRCA1_NM_007294.3 & c.4258C>T(p.Gln1420Ter) & Pathogenic & Nonsense & rs80357305 \\
\hline 24 & BRCA1_NM_007294.3 & c.5266dupC (p.Gln1756Profs) & Pathogenic & Frameshift & rs80357906 \\
\hline 25 & BRCA2_NM_000059.3 & c.6405_6408delCTTA & Pathogenic & Frameshift & rs398122556 \\
\hline
\end{tabular}

* Variant not described in the databases used. 
besides the mother, four other women of the generation above the proband did not present breast cancer, as well as the maternal grandmother.

\section{Family 6}

In family 6 , we counted on two probands of the study: one asymptomatic of 30 years of age (A) and another patient of bilateral breast cancer (B), whose diagnosis was given at the age of 44 years. Proband A meets the NCCN criteria of numbers 1 and 21. She performed genetic tests in which the mutation of the family was confirmed: BRCA1 c.5345G>A: p.Trp1782Ter mutation, a pathogen of the nonsense type. On the other hand, proband $B$ had a diagnosis of invasive ductal carcinoma of the breast at age 44, of the triple negative type. She also performed the genetic test, which confirmed the same A mutation. Among the NCCN criteria, she meets numbers 2, 4, 8, 9 and 10.

The heredogram of this family is extensive, with several patients tested: from the B proband, we found two nephews with haematological neoplasia and three cousins with breast cancer (diagnoses at 38, 51 and 51 years). With the mutated gene, we have one daughter, two brothers, two sisters and two of the three cousins with breast cancer. Several other nephews, siblings, and cousins performed the test and were classified as wild BRCA1.

\section{Family 7}

The proband of family 7 was diagnosed with breast cancer at age 30. Subsequently, at 33, a central nervous system (CNS) metastasis was found and, a year later, a new metastasis in the CNS. Her primary tumor was HER-2 positive (FISH) and Ki67 was expressed in 20\%. Tests were performed on BRCA1, BRCA2, TP53 and CDKN2A genes, with no significant variants found. According to the NCCN criteria, she meets only that of number 2 .

In the heredogram, we have the father with melanoma at age 35 and paternal uncle and grandfather with a diagnosis of lung cancer at 65 and 45 years, respectively. It should be noted that the paternal side of the family consists of only men. The proband has a 25-year-old sister with no history of neoplasia.

\section{Family 8}

In family 8 , we have a proband with diagnosis of breast cancer at 51 years, triple negative tumor and no history of other tumors. A multiplex ligation-dependent probe amplification (MLPA) for the BRCA1 gene was carried out and the seven polymorphisms found were not clinically relevant. Meets criteria 8 and 9 of the NCCN.

The heredogram only shows a history of breast cancer in the mother, whose diagnosis occurred at age 41. It is worth mentioning the absence of neoplasias in both siblings of the proband (45 and 53 years), as well as in both sisters of the mother ( 65 and 60 years) and in the maternal grandmother (deceased at 62 years).

\section{Family 9}

Family 9 had an asymptomatic proband, which was followed-up by a history of bilateral breast cancer in her mother (at 37 and 47 years old). There is little family information since her mother is adopted and her heredogram is unknown. The proband meets the following NCCN criteria: 2,7 and 9. The sequencing of BRCA1 and BRCA2 genes was carried out, with apparently non-pathogenic variant results.

Her heredogram shows bilateral breast cancer in the mother, who has two children: the proband and a man.

\section{Family 10}

The proband of family 10 has as primary tumors a breast carcinoma and an oropharyngeal tumor, diagnosed, respectively, at 51 and 57 years. In addition, a lung tumor was found at age 57. The BRCA1, BRCA2 and TP53 genes were tested; the first two were negative, whereas in the TP53, the pathogenic c.1010G>A:p. Arg337His (R337H) mutation was found, indicating the presence of Li-Fraumeni syndrome. Because NCCN criteria 8, 9 and 10 were presented, the investigation of $\mathrm{HBOC}$ was done, in addition to other syndromes.

In the heredogram, we found a daughter diagnosed with colorectal carcinoma at age 27 and two sisters with breast cancer at 40 and 65 years. On the other side, the father with head and neck cancer, an uncle with cancer of unknown site, in addition to a cousin with testicular cancer diagnosed at age 30 and a cousin with breast cancer diagnosed at age 37 .

\section{Family 11}

The proband of family 11 had a diagnosis of invasive ductal carcinoma of the breast at 31 years of age. The tumor had no HER-2 expression and Ki67 expression was $30 \%$, being of the luminal A subtype. A genetic test was performed on the BRCA1, BRCA2 and CHEK2 genes and no mutation with clinical relevance was found. Of the NCCN criteria, she meets only number 2 .

Her heredogram shows the father with a kidney cancer at age 70 , the paternal aunt with breast cancer at age 55 and the maternal grandfather with a lung tumor presented at an unknown age. We highlight the absence of neoplastic diseases in their three sisters, as well as in any other patient of the same generation of the proband.

\section{Family 12}

The proband of family 12 had a diagnosis of breast cancer at age 39 , with no other tumor. The neoplasia is triple negative with $80 \%$ expression of Ki67. The sequencing and MLPA results for the BRCA1 gene were negative for pathogenic mutations. Among the NCCN criteria, they meet criteria numbers 2 and 8 .

In their heredogram we found a maternal grandmother with colorectal cancer at age 70 and both paternal grandparents with cancer without known primary sites. We highlight the presence 
of two maternal aunts and five uncles and two paternal aunts with no oncological presentation.

\section{Family 13}

In family 13, the proband presented invasive ductal breast cancer at 36 years of age. Ki67 expression of the tumor was $70 \%$, of the luminal type A. Tests were performed for the BRCA1, BRCA2, TP53 and CHEK2 genes, and no pathogenic variation was found. Of the NCCN criteria, they meet numbers 2 and 7.

To the heredogram, the proband is the only one in the family to present neoplastic disease. She has four sisters and three brothers, in addition to six maternal aunts, all without any history of cancer.

\section{Family 14}

Family 14 has a proband whose diagnosis of breast cancer was at age 33, which is their only tumor. A triple negative invasive ductal carcinoma with $90 \% \mathrm{Ki} 67$ expression. Tests were performed on the BRCA1, BRCA2 and TP53 genes, and no mutation of clinical relevance was found. Of the NCCN criteria, the proband complies with those of numbers 2, 4 and 8 .

In the heredogram, we found a maternal aunt with breast cancer at 58 years of age, in addition to a paternal aunt with a head and neck tumor at 40, the maternal grandfather with CNS tumor at unknown age and the paternal grandfather with tumor of site unknown. We highlight the absence of neoplastic disease in both sisters and in the mother, aged 58 years old.

\section{Family 15}

The 15-year-old proband had her breast cancer diagnosed at age 59, being her only cancer, luminal A type, HER-2 negative. There is no mutation in BRCA1 or BRCA2. Of the NCCN criteria, she only complies with number 10.

Her heredogram shows a monozygotic twin sister who did not present any neoplasia. In contrast, three of her other eight sisters had breast cancer, all of them older than 50 years of age. On both sides of the family, no neoplastic presentations were found.

\section{Family 16}

In family 16, we have a proband with diagnosis of breast cancer at age 59, without other neoplasias. The tumor is positive for Ki67 (80\%) and triple negative expression. The BRCA1 sequencing test was performed and no pathogenic mutations were found.

To the heredogram, we observed a sister with cervical cancer at 43 years of age and two paternal aunts with neoplasias - cervix (80 years) and breast (50 years) - and the father with prostate cancer at age 75. A paternal cousin (daughter of the aunt with cervical cancer) also had breast cancer at age 60 . The paternal grandmother with hematologic neoplasia at age 82 and the paternal-maternal great-grandfather with skin cancer were also found.

\section{Family 17}

The proband of family 17 was diagnosed with breast cancer at age 37, a HER2-negative invasive ductal carcinoma, luminal type A. In the genetic tests, the BRCA1 and BRCA2 genes were sequenced, and a variant mutation of uncertain significance was found in each of the sequencing. Of the NCCN criteria, she presents those of numbers 2 and 7 .

Her heredogram shows a sister and a paternal aunt with breast cancer (ages at diagnosis of 37 and 70 years, respectively) and a maternal uncle with head/neck cancer. On the paternal side, there is a cousin with haematological neoplasia and both grandparents with cancer: the grandfather in the head and neck region and the grandmother in the gastrointestinal tract. It is worth noting the presence of two other sisters of the proband without any history of neoplasias.

\section{Family 18}

The proband of family 18 was diagnosed with breast cancer Ki67 expressed in 35\%, HER-2 positive, luminal A type, at age 35. His BRCA1 and BRCA2 tests were negative. Among the NCCN criteria, it meets numbers 2 and 7.

The heredogram presents with little information, since the mother is adopted and there is no knowledge of the father's history. We highlight the presence of one sister and three brothers of the proband, none with cases of neoplasia.

\section{Family 19}

In family 19, we have a proband whose first diagnosis of breast cancer occurred at 37 years of age, being this their only cancer. The neoplasia expresses HER-2 (FISH) and 10\% Ki67. In genetic testing, no mutations were found in either the BRCA1 or BRCA2 genes. As regards the NCCN criteria, they meet the criteria of numbers 2, 4, 9 and 10 .

The heredogram shows three cases of breast cancer at a young age: the daughter of a female maternal cousin (diagnosis at age 19) and two other daughters of a male maternal cousin (diagnoses at 26 and 36 years of age). We also found a case of bilateral breast cancer, the sister of the paternal grandfather (64 years at diagnosis) and a case of gastrointestinal cancer, the paternal grandmother. It should be noted that there are only men in the paternal side of the family and only women in the maternal side, none of whom have a history of neoplastic disease. In addition, the proband has three other male brothers.

\section{Family 20}

Family 20 has a proband whose first diagnosis of breast cancer was at age 57 - Ki67 tumor expressing 5\%, HER-2 positive (FISH), luminal type $\mathrm{B}$. In genetic tests, no clinically significant variants were found for BRCA1 and for BRCA2 and CHEK2. Of the NCCN criteria, criteria 9, 10 and 11 are met. 
The heredogram shows that, of the three siblings of the father (two women and one man), two had neoplasias: one was diagnosed with breast cancer at age 50 and of ovarian cancer at 60 ; the other had breast cancer at age 55 and stomach cancer at 65 . There is also a cousin with breast cancer at age 40 (daughter of the aunt with breast and stomach cancer). On the maternal side, we found an aunt with CNS tumor (55 years) and an uncle with bladder tumor ( 65 years). It should be noted that the proband has two other sisters without diagnosis of breast cancer.

\section{Family 21}

Family 21 has a proband whose diagnosis of breast cancer occurred at age 45 , this being their only tumor -luminal type A and HER-2 negative. In the genetic tests, mutations with clinical significance for BRCA1 and BRCA2 were not found. Among the NCCN criteria, it presents those of number four and 10.

The heredogram evidences the genetic origin of the tumor as being from the maternal side, since of the three maternal aunts of the proband, two had breast cancer (at ages 53 and 63). In addition, the maternal grandmother also had breast cancer (at 75 years) and a maternal uncle had colorectal cancer (53 years of age).

\section{Family 22}

The proband of family 22 was diagnosed with invasive ductal carcinoma of the breast at age 47 and did not present any other tumor. The tumor has Ki67 expression of $90 \%$, triple negative. In the genetic tests, a duplication was found in the exon 20 of the BRCA1 gene, which is a pathogenic mutation. No information on this variant was found in the databases searched ${ }^{6}$. Of the NCCN criteria, they meet numbers 2, 4, 8, 9, 10 and 11 .

In the heredogram, the proband presents a maternal cousin with breast cancer at age 55. On the paternal side, two other cousins (sisters among themselves) had breast tumors at 55 and 59 years of age. A third paternal cousin also had the same cancer at age 46, as well as another paternal cousin (male) with CNS tumor and a nephew of that paternal cousin with hematologic cancer.

\section{Family 23}

Family 23 has two probands. Proband A was diagnosed with ovarian cancer at age 66, with expression of $40 \% \mathrm{Ki} 67$ and clinical stage III. A genetic mutation was found in the BRCA1 gene: c.4258C >T (p.Gln1420Ter), pathogenic, nonsense type, confirming the HBOC syndrome. Of the NCCN criteria, she complies with those of numbers 1,15 and 20. In turn, proband B, daughter of proband $\mathrm{A}$, presented invasive ductal breast carcinoma at 45 years of age, with expression of $20 \%$ of Ki67, luminal type A Proband B meets criteria 1, 2, 11 and 20 of the NCCN.

To the heredogram, we observed only one uncle and an aunt of proband A with diagnoses of gastrointestinal cancer: he at 50 and she at 60 years of age.

\section{Family 24}

In family 24 , we have a proband whose diagnosis was ovarian carcinoma at 65 years of age, without other tumors. Genetic testing showed the mutation in the BRCA1 c.5266dupC:p.Gln1756Profs gene, pathogenic, type frameshift. Among the NCCN criteria, it meets those of numbers 2,15 and 20.

In the heredogram, we see that their two daughters had breast cancer (at 35 and 50 years of age). The 50-year-old daughter also took the genetic test, confirming the same mutation in BRCA1. The proband has two sisters, both with a history of cancer: one had a gastrointestinal tumor at age 85 and the other had breast and ovarian cancer, both at 38 years of age. That same sister also had a daughter with bilateral breast cancer (49 years) and a granddaughter with breast cancer at age 28 . The other brothers of the proband, four men, had no history of neoplasias. As for the nieces: one had breast and ovary tumors (50 years of age), another had breast tumor at age 30 and the third, breast tumor at 25 years. It is worth noting the presence of several women in the generation below the proband.

\section{Family 25}

Family 25 has a proband diagnosed with invading ductal breast tumor at age 29, with expression of 30\% Ki67, HER-2 positive (FISH), luminal B. The following mutation was found in the BRCA2 gene: c.6405_6408delCTTA, pathogenic, frameshift. Of the NCCN criteria, the proband meets criteria numbers 2 and 20 .

The heredogram shows a sibling with hematologic malignancy at age 18 , as well as two other sisters with the same mutation as the patient and one sister without the mutation. The other two brothers did not perform the genetic test. On the maternal side, an aunt presented gastrointestinal cancer (70 years) and the grandmother, lung cancer (76 years). On the parental side, we have an uncle with CNS tumor (62 years), another uncle with gastrointestinal tumor (55 years) and another uncle with prostate tumor (63 years). The paternal grandfather had a tumor of unknown place by the family. There is still one cousin with prostate tumor at age 54 and his son with neuroblastoma at 4 years of age.

\section{DISCUSSION}

In the studied population, $85 \%$ of the patients had breast cancer, with a mean age at diagnosis of 42 years. The prevalence of pathogenic germ mutation in the BRCA1 and BRCA2 genes was 22 and $3.7 \%$, respectively. In addition, the prevalence of mutation in the TP53 gene responsible for Li-Fraumeni syndrome was 3.7\%. Remarkably, the age at diagnosis in patients with detected mutation was higher than the age at the same diagnosis in patients without mutations detected. One of the possible explanations for this fact is that other genes associated with HBOC could be present in this population. 
Studies conducted in the European population report different rates of prevalence of mutations in BRCA1 and BRCA2 genes. A British study including 1,435 patients diagnosed with breast cancer before age 55 screened for mutations in these genes by analyzing the entire sequence - introns and exons - of both by polymerase chain reaction (PCR). Mutations were detected in $0.7 \%$ of the population for BRCA1 and 1.3\% for BRCA2 $2^{7}$. Different prevalences were reported in a study conducted in Dutch families with a family history of breast cancer, with mutations in the two genes detected in 12.3 and $5 \%$, respectively ${ }^{8}$.

The prevalence of these mutations was previously characterized in some Brazilian centers. A study conducted in 402 breast cancer patients not evaluated for genetic risk in Rio de Janeiro described the prevalence of $1.5 \%$ of mutations in the BRCA1 gene and $0.75 \%$ in BRCA2, with the mean age at diagnosis of breast cancer of 46 years 9 . Considering the patients with a diagnosis age of less than 40 years, mutations were detected in $5.7 \%$ of the population'. The relatively low frequency of mutations in this study may be a result of the wide inclusion of patients whose genetic risks prior to the test were not evaluated, and the mutation test in these two genes was limited to the detection of changes restricted to hotspots of mutations most frequently found in the literature; thus, it is possible that this strategy underestimated the real predominance in this population.

A study conducted at a São Paulo institution characterized 349 patients at high risk for HBOC by means of complete sequencing of the coding regions and splicing in the BRCA1 and BRCA2 genes. The reported prevalence of mutations for the former was $14 \%$, while for the latter it was $7 \%$. Notably, 6 new mutations were identified and approximately $90 \%$ of the mutations detected had not previously been described in the Brazilian population $^{5}$. Mutations were described in practically all exons in the BRCAl gene, with frameshift type in exon $20^{5}$ being characteristically prevalent; in BRCA2, in the same way, mutations have been described in almost all exons ${ }^{5}$. Thus, the importance of the complete evaluation of the exons of BRCA1/2 genes in search of significant mutations is emphasized, in order to increase the sensitivity of the genetic tests and not to underestimate the prevalence of these mutations.

Indeed, this study described three distinct mutations in the families, two in BRCAl and one in BRCA ${ }^{25}$. The c.5266dupC:p. Gln1756Profs mutation in the BRCAl gene was the most frequently found in the aforementioned study from São Paulo, described in 18 families, representing $36 \%$ of the total mutations found in that study ${ }^{5}$. This mutation was found in one patient in this study, representing $33 \%$ of families with BRCA1/2 mutations. Likewise, the only mutation found in the BRCA2 gene of this study, namely c.6405_6408dCTTA, was described in two families analyzed in the São Paulo study. Two mutations found in this sample had not been previously characterized in the Brazilian population: both c.4258C >T (p.Gln1420Ter) and c.5345G>A (p.Trp1782Ter), pathogenic, nonsense, were associated with the $\mathrm{HBOC}^{6}$ phenotype. These two mutations never described in Brazil can represent regional variants, since the constitution of the population of the South of the country is quite different from other regions.

The population of the Brazilian Northeast was characterized by a study conducted with 106 breast cancer carriers with high risk for HBOC evaluated for mutations in BRCA1 genes with complete sequencing, BRCA2 and TP53 by screening for more frequent mutations a priori ${ }^{10}$. The mean age at diagnosis was 43 years, $91 \%$ of patients with breast cancer and $4.7 \%$ of ovarian cancer $^{10}$. Mutations in the BRCA1 gene were detected in $8.4 \%$ of the patients, in TP53, in $0.9 \%$ and no patient was a carrier of BRCA2 mutation. In addition, in line with that reported in the population of the present study, the majority of breast cancer patients with mutations detected were triple negative in the molecular evaluation of cancer.

It is known that the association between the triple negative phenotype is more consistent in BRCA1 gene mutations than in BRCA2 ones ${ }^{11}$. A study conducted in a population consisting of 314 patients with triple negative breast cancer demonstrates this difference ${ }^{11}$ : considering only patients with estrogen receptor (ER) and progesterone (PR) expression lower than $1 \%$, the prevalence of BRCA1 mutations was $30 \%$, whereas in BRCA2 it was $7 \%^{11}$. Interestingly, these proportions were the same both for the group with ER and PR expressions of 1 to $9 \%$ and for less than $1 \%$, which suggests that there are no biological differences between the two groups, with implications for the indication of tracing for HBOC and therapy ${ }^{11}$. It should be noted that of our patients with mutation, three had triple negative tumors, two with mutation in BRCA1 and one mutation in TP53.

Although there is no definite answer about the phenotypic differences between BRCA1 and BRCA2 in breast cancer, numerous hypotheses regarding the differential function that both proteins encoded by these genes exert in the cell have been described to explain this issue ${ }^{12}$. It is believed that BRCAl protein, whose function in DNA repair by chromatid homology is well established, exerts regulatory functions on other genes, possibly including estrogen and progesterone receptors ${ }^{12}$. In addition, it is possible that the BRCA1 gene haplotype includes genes that modulate expression or increase susceptibility to hormone receptor repression, thereby increasing the prevalence of breast neoplasms with negative receptors ${ }^{12}$. Thus, taking into account the low prevalence of mutations in the BRCA2 genes reported in this study and in the descriptive study of the Northeastern population, it can be said that the Brazilian population with HBOC would be particularly susceptible to presenting more triple negative phenotypes.

All patients included in this study had a family history for some type of cancer, with breast cancer being most frequently one found. It is known that the genes associated with HBOC present an autosomal dominant inheritance of age-dependent varied penetrance. For example, for mutations in the TP53 gene 
constituting the Li-Fraumeni syndrome, the risk of developing neoplasms up to 60 years of age is $90 \%^{13}$. For the BRCA1 and BRCA2 genes, the chance of developing breast neoplasia during life is described as varying from 50 to $80 \%$ and from 40 to $70 \%$, respectively ${ }^{14}$. However, the penetrance of these genes is the subject of much debate in the literature. In this study, the penetrance evaluated by the percentage of individuals affected in relation to the total of individuals in the generation, considering only those at risk for mutations, was approximately $22 \%$.

Among the patients whose mutations were detected, some notable features regarding family history were highlighted by heredograms. For example, the patient with mutated TP53 with a personal history of three neoplasms presents a characteristic heredogram of an autosomal dominant condition of high penetrance, evidenced by the fact that all generations were affected by neoplasms described in the spectrum of Li-Fraumeni syndrome. On the contrary, in the heredograms of patients with BRCA1 mutations, the phenotype was more restricted to breast cancer and the penetrance was variable, with generations of not-affected individuals. It should also be considered that, in the case of families with mutated BRCA1, the presence of generations consisting solely of men may limit the expression of the phenotype related to the gene, given the possible lower penetrance in men or the lower probability of the diagnosis of breast cancer in men.

In relation to the criteria served by the families analyzed in this study, it was verified that 9 was the most frequent: personal history of breast cancer at any age associated with a family history of breast cancer at age 50 years or less at diagnosis. This criterion was present in 11 families (61\%), followed in frequency by criteria 2 and 8, which were found in 10 and 9 families, respectively. This scenario may suggest that these criteria are more sensitive for identification of HBOC in the present population.

This study described the ages at diagnosis of breast cancer among the generations in the families of the probands. Typically, the mean ages at diagnosis decreased with time between generations, which might suggest the phenomenon of anticipation. Previous studies have reported average differences in the ages with which probands carrying mutations in BRCA1/2 genes were diagnosed with breast cancer. However, there is an extensive debate in the literature regarding this phenomenon for $\mathrm{HBOC}$ patients.

A large study conducted by the University of Chicago retrospectively evaluated patient charts at the institution's oncology clinic from 1992 to $2013^{15}$. There were 176 families and their heredograms were evaluated ${ }^{15}$. The mean differences in the ages at diagnosis were not significant after adjustment for variables related to the time of birth of the patients ${ }^{15}$. Thus, it is not possible to exclude that the lower ages at diagnosis of breast cancer detected over time are caused by different prevalence in the expression modifiers of the breast cancer phenotype, as risk factors for breast neoplasia, as well as the effects of the screening programs that have been instituted over time.

In addition, from the point of view of molecular genetics, the genetic mechanisms associated with the anticipation phenomenon are best described in genes exhibiting unstable expansions of DNA segment repetitions, such as in diseases associated with polyglutamine proteins, such as Huntington's disease, or other conditions that affect the CNS, such as Fragile X syndrome ${ }^{16}$. However, studies conducted in patients with Li-Fraumeni syndrome have reported that a polymorphism in the MDM2 gene, which encodes a protein that increases the degradation of the p53 protein, was significantly associated with earlier clinical manifestations of this syndrome ${ }^{17}$. In addition, the shortening of telomeres in patients with Li-Fraumeni was also implicated as a possible mechanism for the phenomenon of anticipation in this syndrome $^{17}$. Thus, possible BRCA1/2 expression modifying genes could be associated with earlier clinical manifestations over time.

This study has some important limitations. Firstly, it is just a description of the population, since there was no available sampling power for association tests. In addition, some important phenotypic characteristics, such as the stage of diagnosis and therapeutics used, have not been described. Importantly, our estimates of the prevalence of mutations in $\mathrm{HBOC}$ associated genes certainly suffer from several limitations. The small amount of individuals in the sample is a limiting factor. In addition, there is a relevant selection bias, since the patients included are only those who had access to the oncogenetics clinic of Hospital Erasto Gaertner. Other important biases are those related to family history, so if, on the one hand, many heredograms had incomplete information, others might have emphasized the family history component of cancer and age at recall bias.

\section{CONCLUSION}

We believe it to be the first descriptive study of a population at high risk for HBOC in the population of Paraná. It was possible to describe two pathogenic variants of BRCAl that were not previously characterized in studies in the Brazilian population. It should be emphasized that there was a comprehensive inclusion of the patient's family histories, so that all the available heredograms were scanned and included in the study. In addition, a limited evaluation of important HBOC variables, such as anticipation and penetrance, and estimates of the proportions of genes involved were possible. Prevalence estimates are in line with previous descriptions in the Brazilian population, so there is a preponderance of $\mathrm{BRCA} 1$ over $\mathrm{BRCA} 2$ in these patients. Penetrance and anticipation data are also supported in Brazilian and worldwide literature. Finally, the importance of more studies, especially with the power to evaluate other variables, that characterize the Brazilian population regarding both the phenotype and the $\mathrm{HBOC}$ genotype, is highlighted. 


\section{REFERENCES}

1. Instituto Nacional de Câncer José Alencar Gomes da Silva. Estimativa 2016: incidência de câncer no Brasil. Brasil: Ministério da Saúde/Instituto Nacional de Câncer; 2016.

2. National Comprehensive Cancer Network. NCCN Clinical Practice Guidelines in Oncology. Pensilvânia: National Comprehensive Cancer Network; 2016.

3. Foulkes WD. Inherited susceptibility to common cancers. N Engl J Med. 2008;359(20):2143-53. https://doi.org/10.1056/ NEJMra0802968

4. Chen S, Parmigiani G. Meta-analysis of BRCA1 and BRCA2 penetrance. J Clin Oncol. 2007;25(11):1329-33. https://doi. org/10.1200/JCO.2006.09.1066

5. Fernandes GC, Michelli RA, Galvão HC, Paula AE, Pereira R, Andrade CE, et al. Prevalence of BRCA1/BRCA2 mutations in a Brazilian population sample at-risk for hereditary breast cancer and characterization of its genetic ancestry. Oncotarget. 2016;7. https://doi.org/10.18632/oncotarget.12610

6. Landrum MJ,LeeJM, Benson M, Brown GR, Chao C, Chitipiralla S, et al. ClinVar: improving access to variant interpretations and supporting evidence. Nucleic Acids Res. 2018 Jan 4. https:// dx.doi.org/10.1093\%2Fnar\%2Fgkx1153.

7. Anglian Breast Cancer Study Group. Prevalence and penetrance of BRCA1 and BRCA2 mutations in a populationbased series of breast cancer cases. Anglian Breast Cancer Study Group. Br J Cancer. 2000;83(10):1301-8. https://doi. org/10.1054/bjoc.2000.1407

8. Petrij-Bosch A, Peelen T, van Vliet M, Eijk RV, Olmer R, Drüsedau $\mathrm{M}$, et al. BRCAl genomic deletions are major founder mutations in Dutch breast cancer patients. Nat Genet. 1997;17(3):341-5. https://doi.org/10.1038/ng1197-341

9. Gomes MCB, Costa MM, Borojevic R, Monteiro ANA, Vieira R, Koifman S, et al. Prevalence of BRCA1 and BRCA2 mutations in breast cancer patients from Brazil. Breast Cancer Res Treat. 2007;103(3):349-53. https://doi.org/10.1007/s10549-006-9378-6
10. Felix GE, Abe-Sandes C, Machado-Lopes TM, Bomfim TF, Guindalini RSC, Santos VCSAR, et al. Germline mutations in BRCA1, BRCA2, CHEK2 and TP53 in patients at high-risk for HBOC: characterizing a Northeast Brazilian Population. Hum Genome Var. 2014. https://dx.doi.org/10.1038\%2Fhgv.2014.12

11. Sanford RA, Song J, Gutierrez-Barrera AM, Profato J, Woodson A, Litton JK, et al High incidence of germline BRCA mutation in patients with ER low-positiva/PR low-positive/HER-2 neunegative tumors. Cancer. 2015;121(19):3422-7. https://dx.doi. org/10.1002/cncr.29572

12. Roy R, Chun J, Powell SN. BRCA1 and BRCA2: Differente roles in a common pathway of genome protection. Nat Rev Cancer. 2011;12(1):68-78. https://dx.doi.org/10.1038/nrc3181

13. Lustbader ED, Williams WR, Bondy ML, Strom S, Strong LC. Segregation analysis of cancer in families of childhood softtissue-sarcoma patients. Am J Jum Genet [Internet]. 1992 [acessado em $1^{\circ}$ dez. 2016];51(2):344-56. Disponível em: http:// www.ncbi.nlm.nih.gov/pubmed/1642235

14. Petrucelli N, Daly MB, Feldman GL. Hereditary breast and ovarian cancer due to mutations in BRCA1 and BRCA2. Genet Med. 2010;12(5):245-59. https://dx.doi.org/10.1097/ GIM.0b013e3181d38f2f

15. Guindalini RSC, Song A, Fackenthal JD, Olopade OI, Huo D. Genetic Anticipation in BRCA1/BRCA2 Families After Controlling for Ascertainment Bias and Cohort Effect. Cancer. 2016:1913-20. https://doi.org/10.1002/cncr.29972

16. Wells RD. Molecular basis of genetic instability of triplet repeats. J Biol Chem [Internet]. 1996 [acessado em $1^{\circ}$ dez. 2016];271(6):2875-8. Disponível em: http://www.ncbi.nlm.nih. gov/pubmed/8621672

17. Bond GL, Hu W, Bond EE, Robins H, Lutzker SG, Arva NC, et al A Single Nucleotide Polymorphism in the MDM2 Promoter Attenuates the 53 Tumor Suppressor Pathway and Accelerates Tumor Formation in Humans. Cell. 2004;119(5):591-602. https://dx.doi.org/10.1016/j.cell.2004.11.022 


\section{Appendix}

Family 1
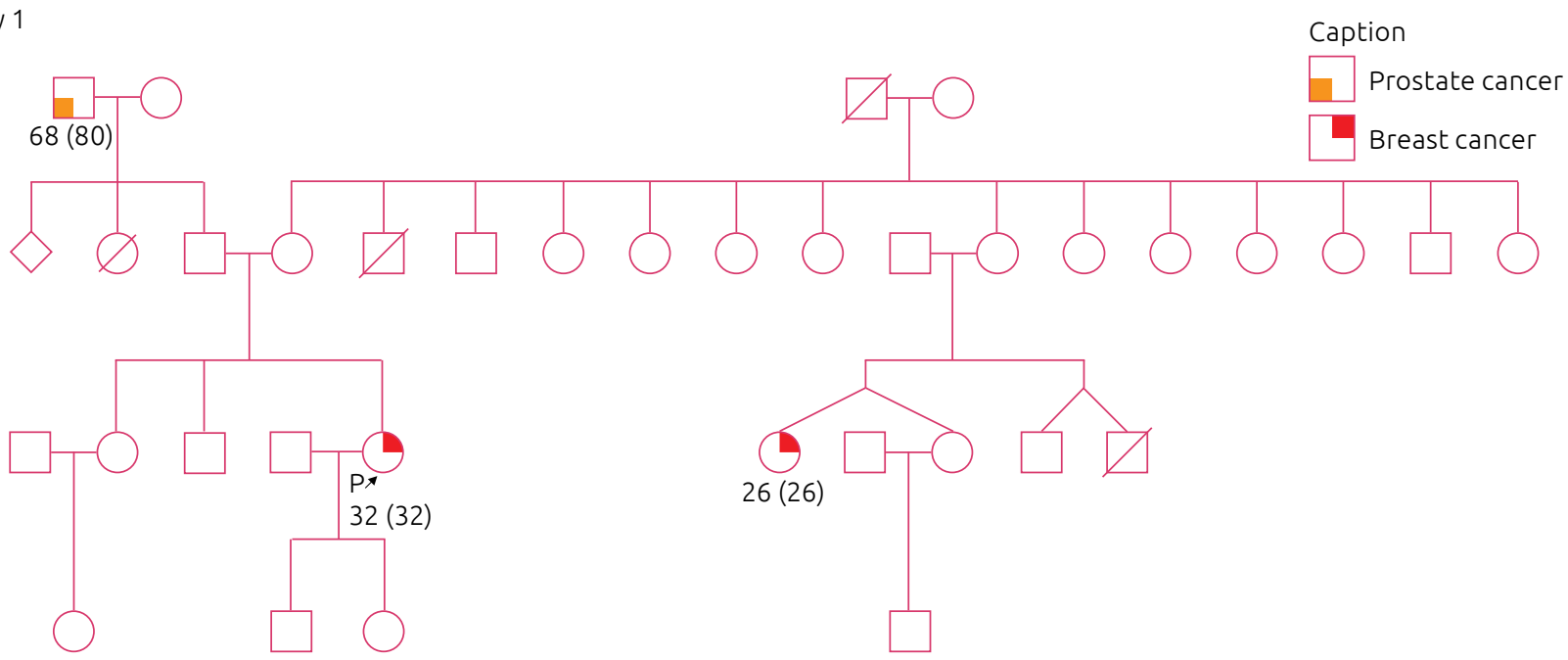

Caption

Breast cancer

Family 2

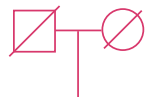

- Cancer without location

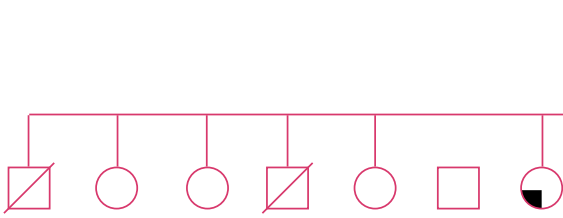

$49(47)$

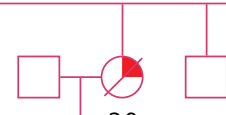

30

- Ovarian cancer
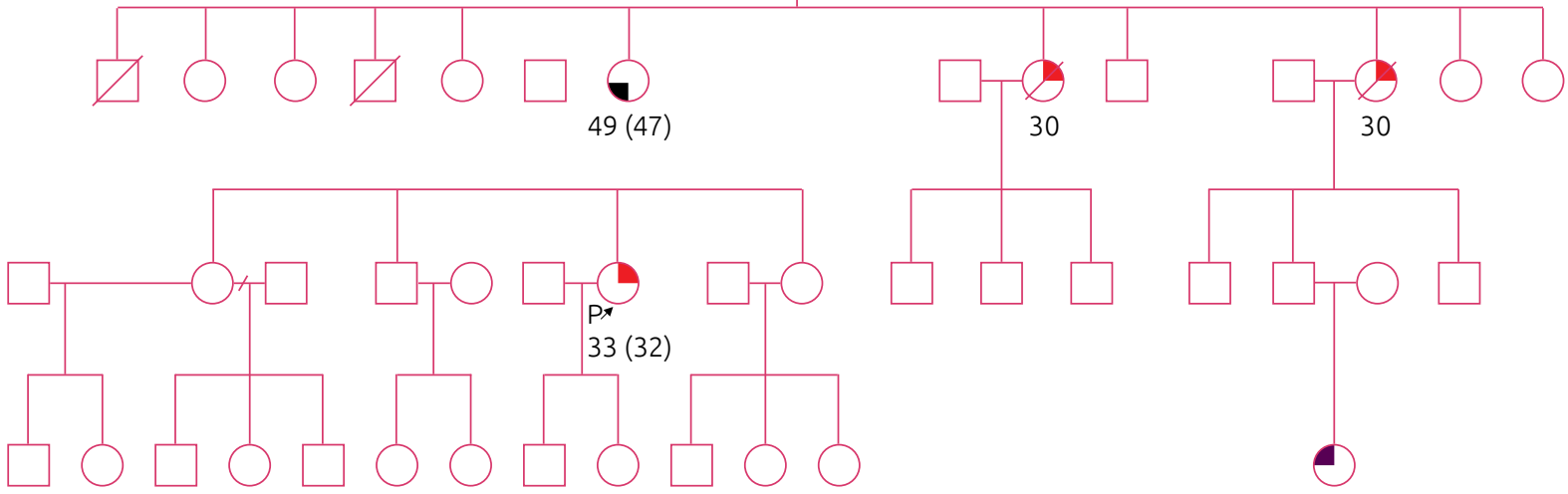

Family 3

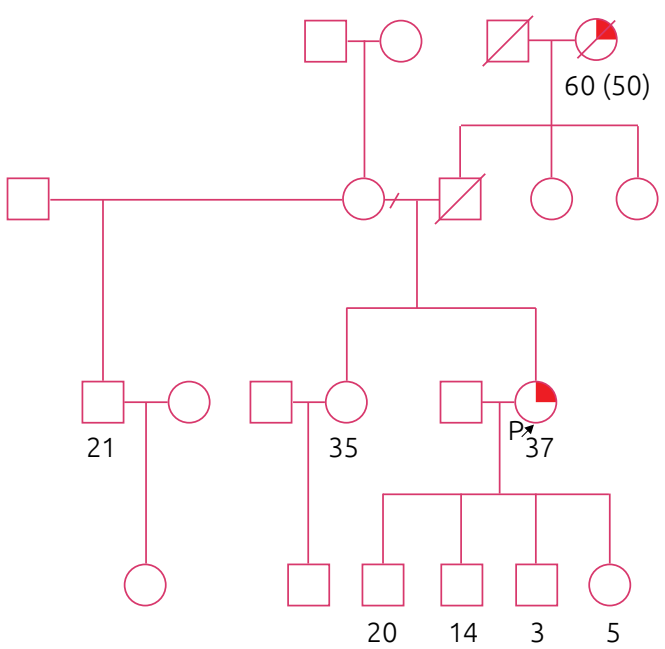

Caption

Breast cancer 
Family 4

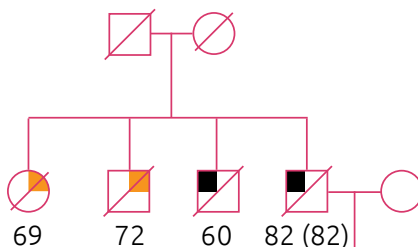

69

$6082(82)$

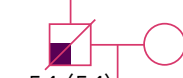

$54(54)$

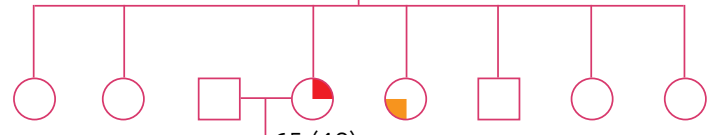

65 (48)

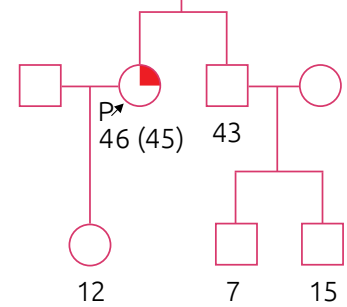

Family 5

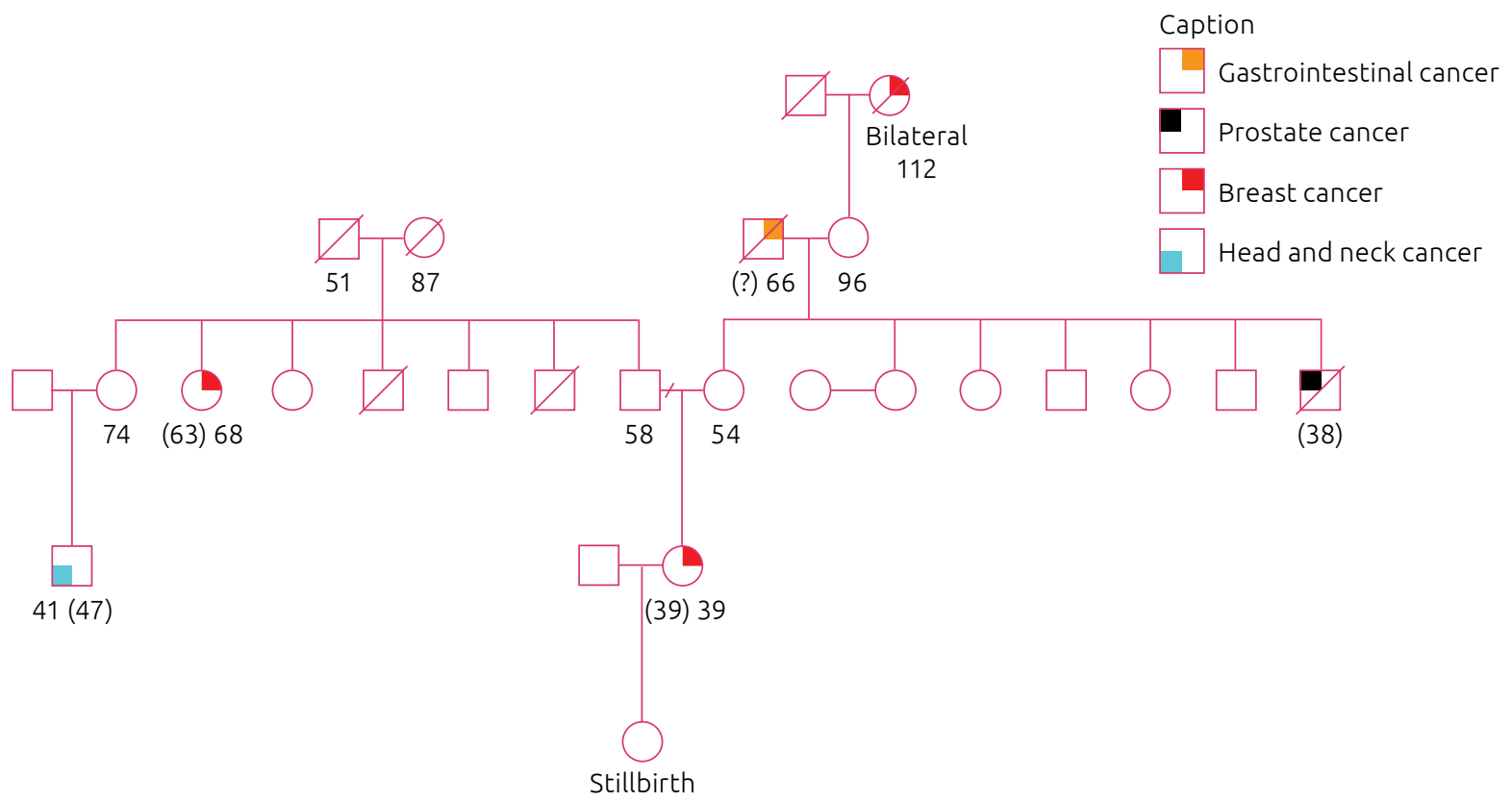



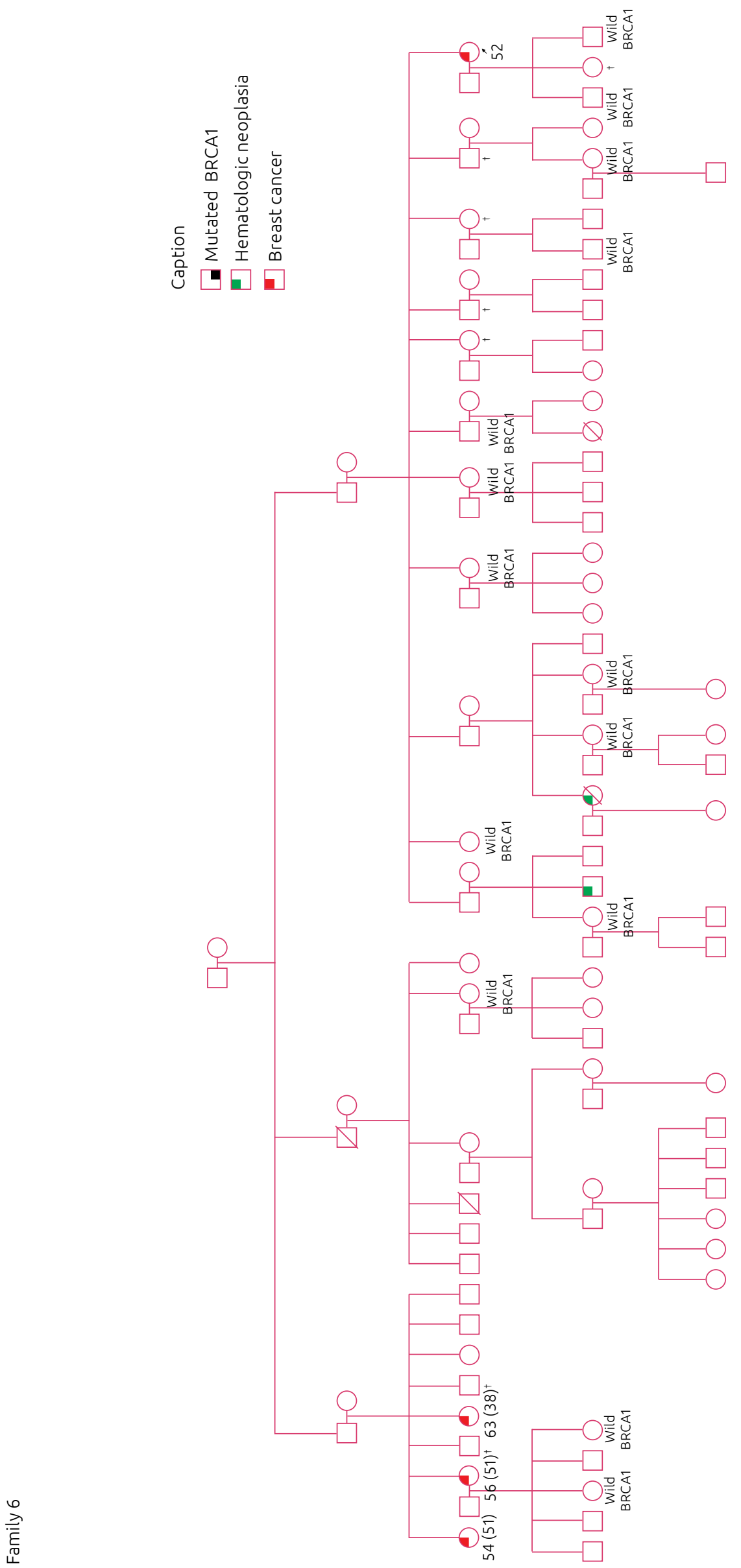
Family 7

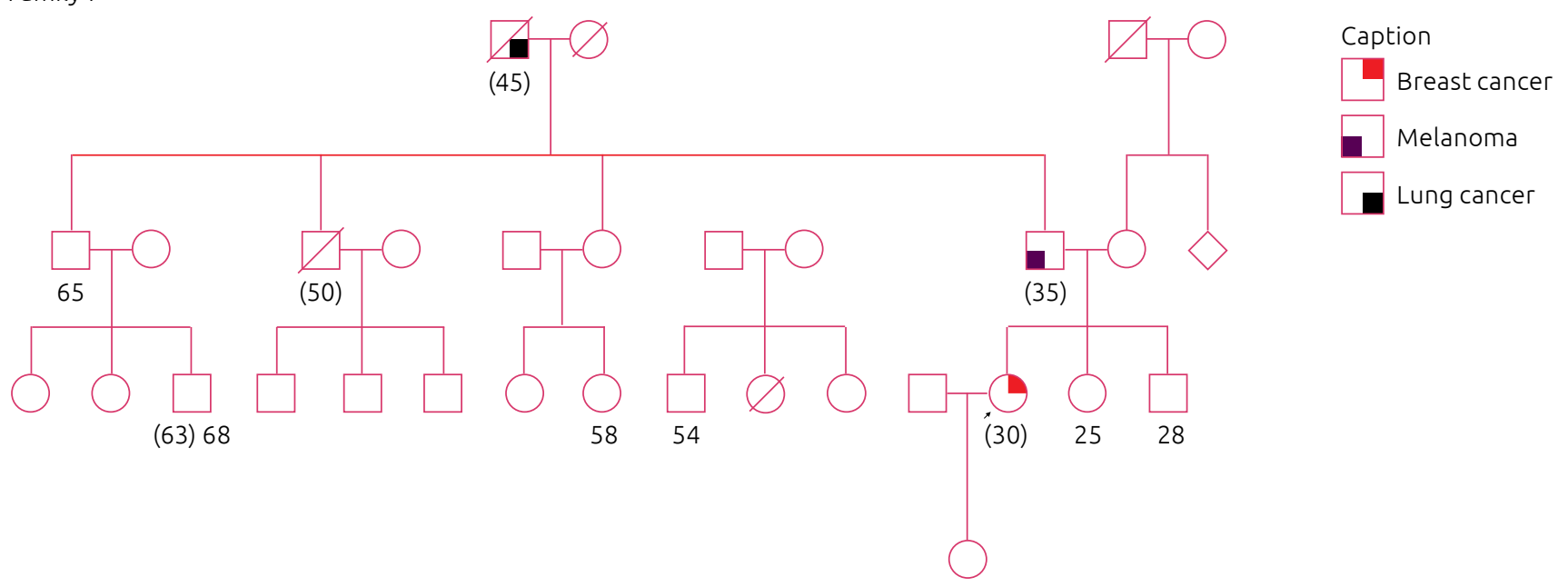

Family 8

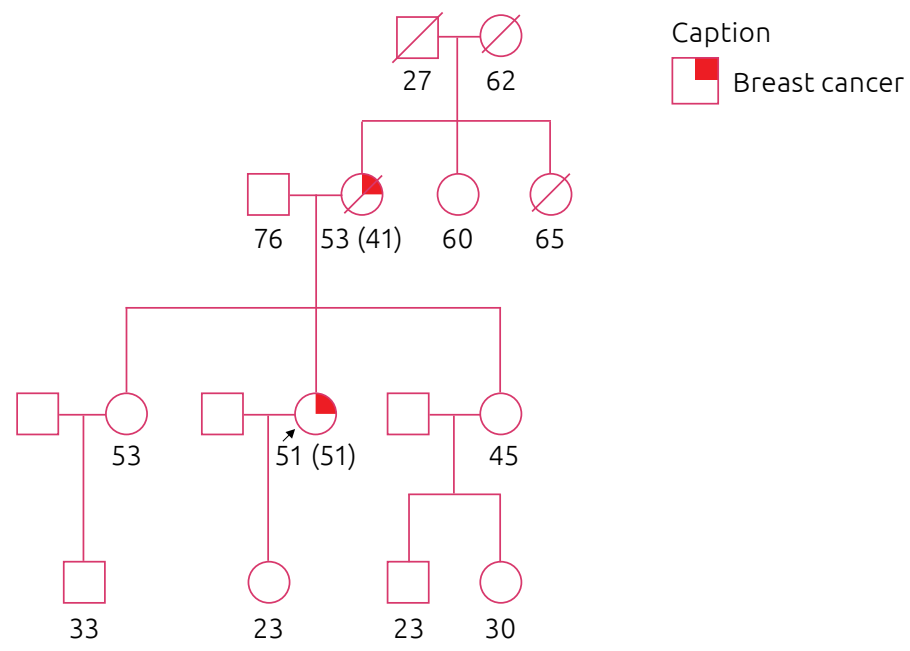

Family 9

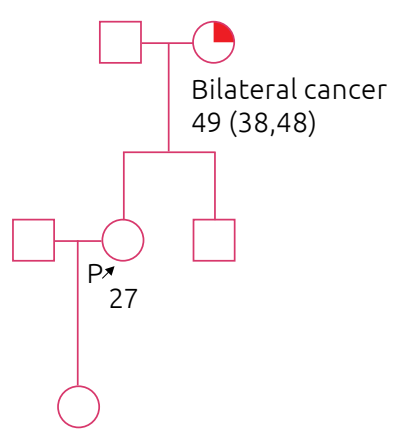

Caption

$\square$ Breast cancer 
Family10

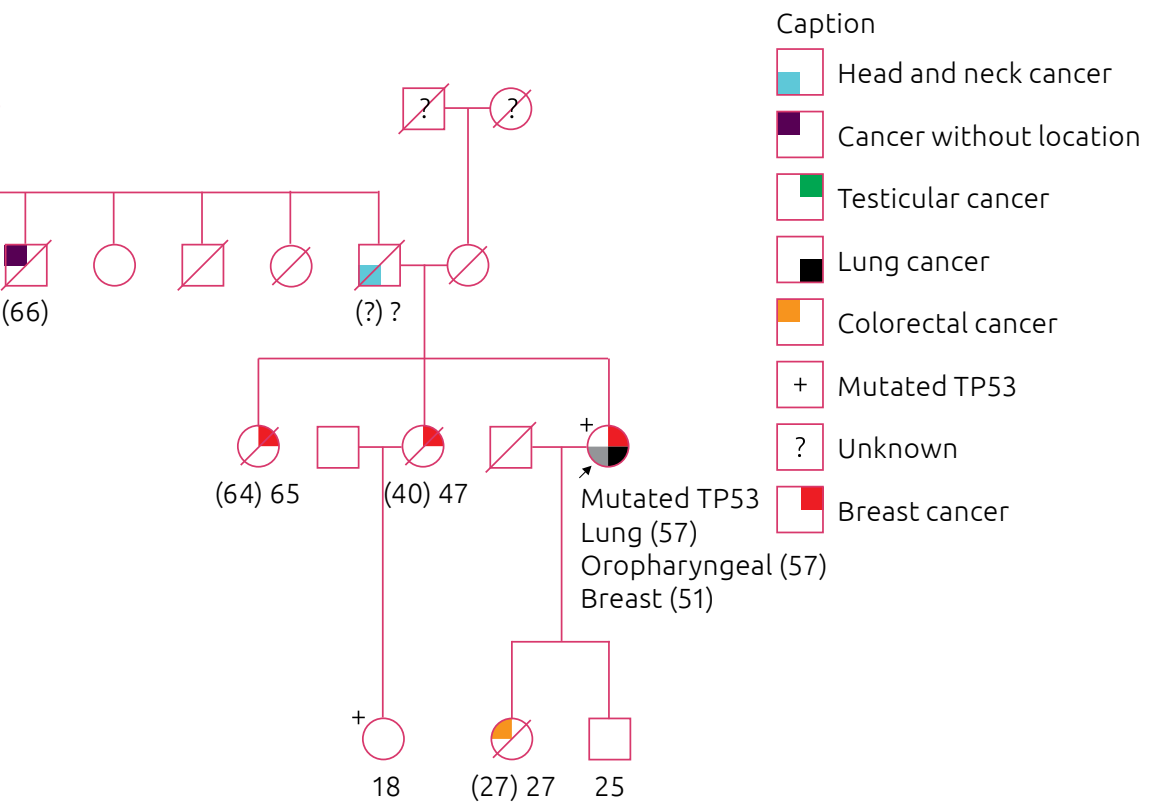

Family 11

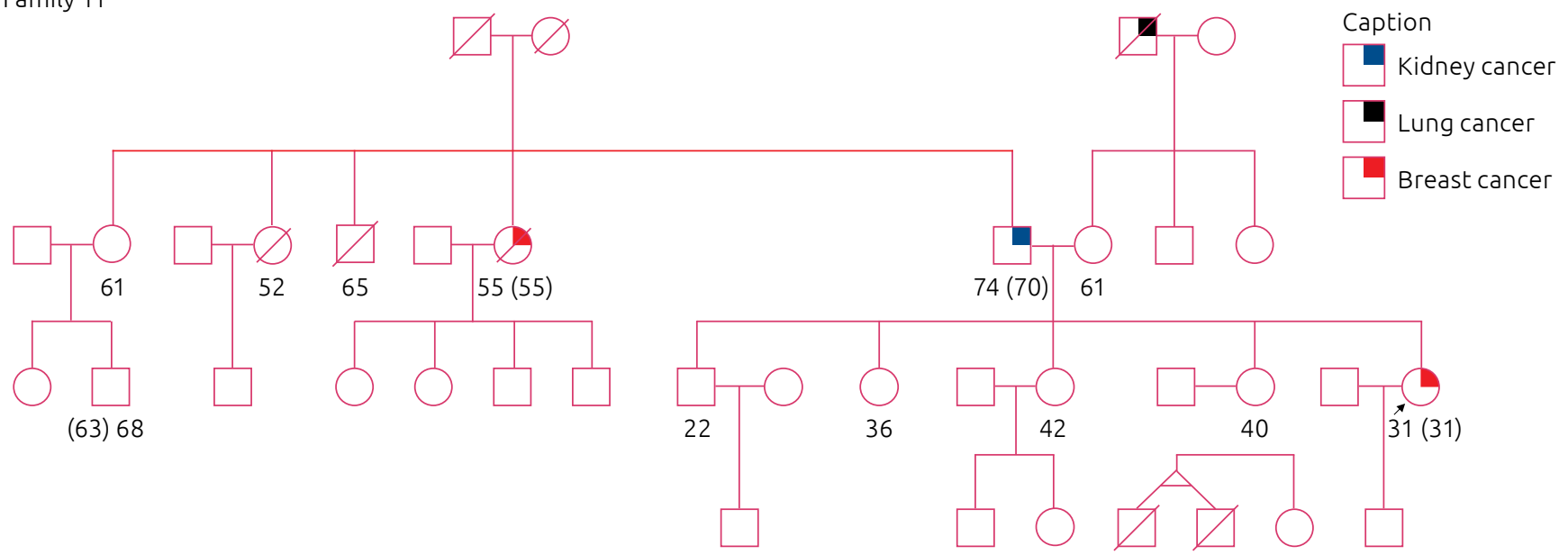

Family 12

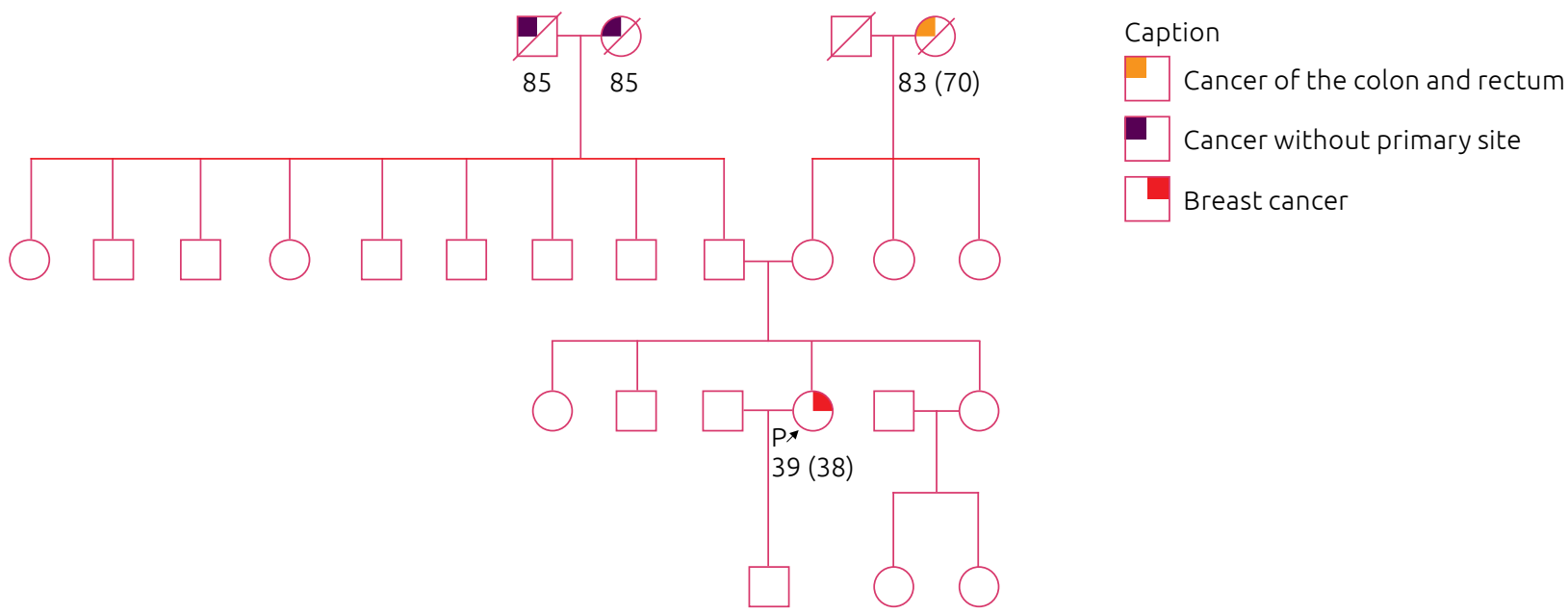


Family 13

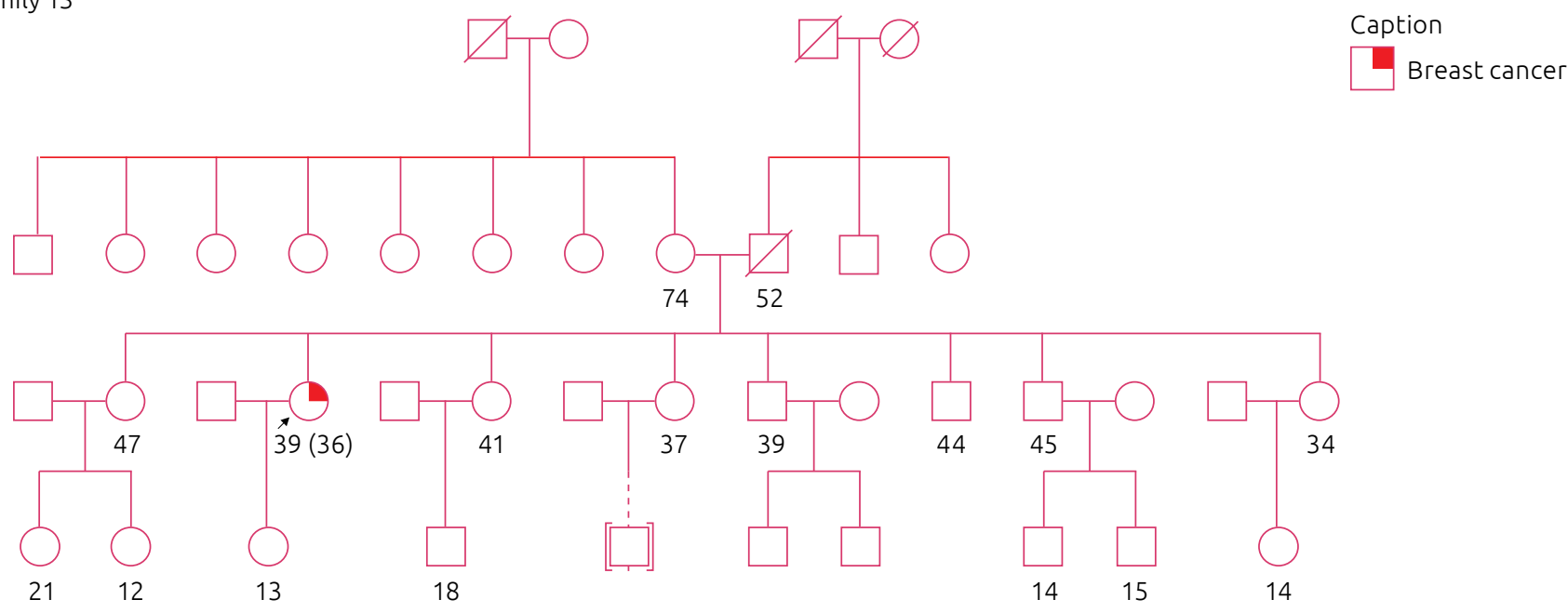

Family 14

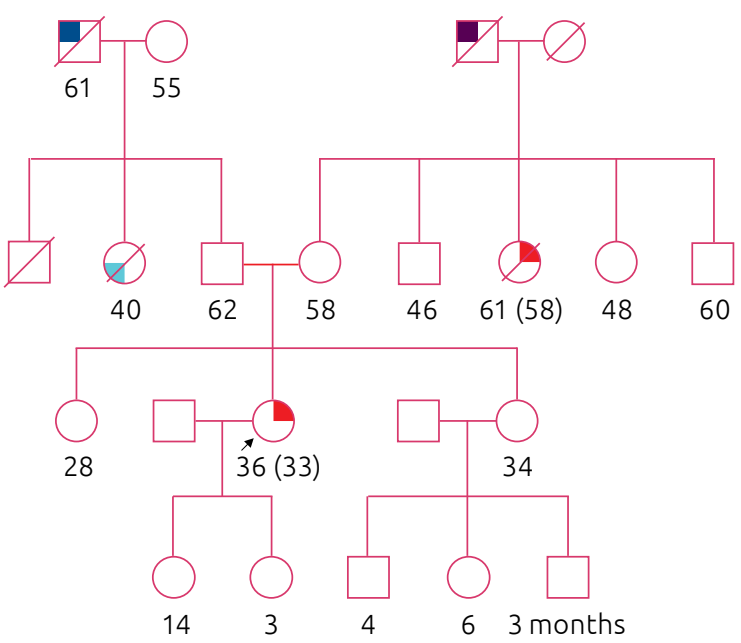

Caption

Breast cancer

Bladder cancer

$\square$ Head and neck cancer

- Cancer without site

- Cancer of the central nervous system

Family 15

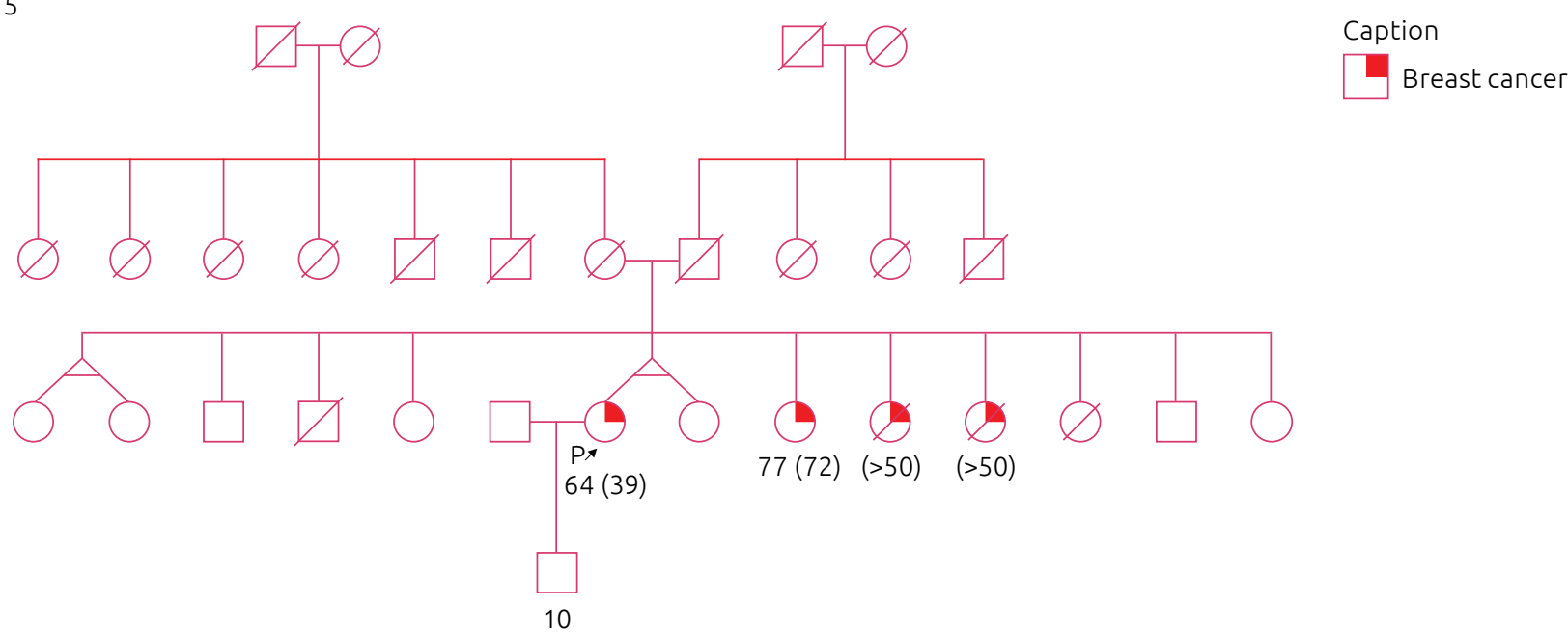


Family 16
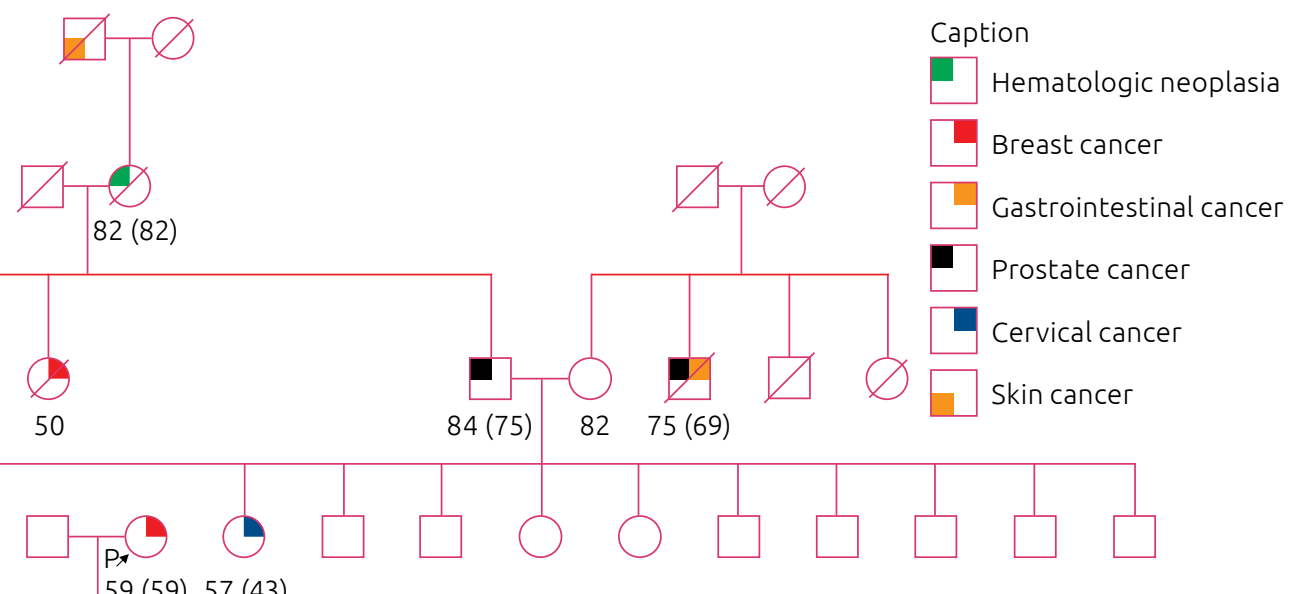

60

$82(82)$
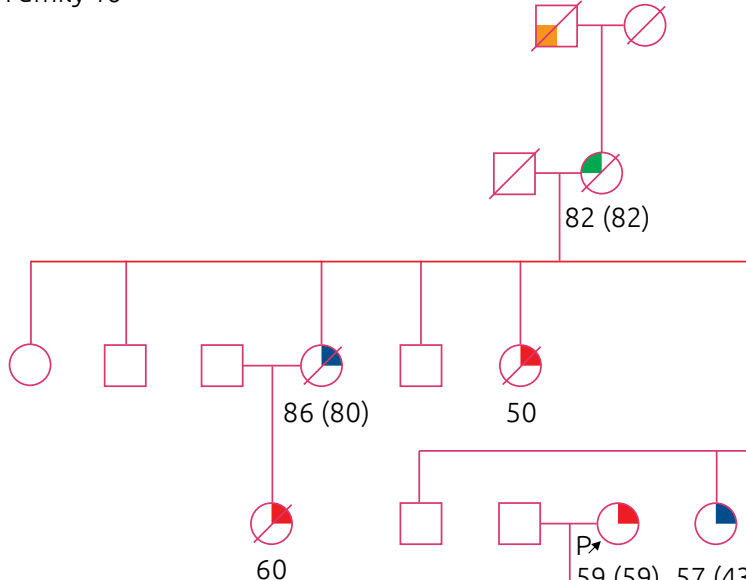

59 (59) 57 (43)

Family 17
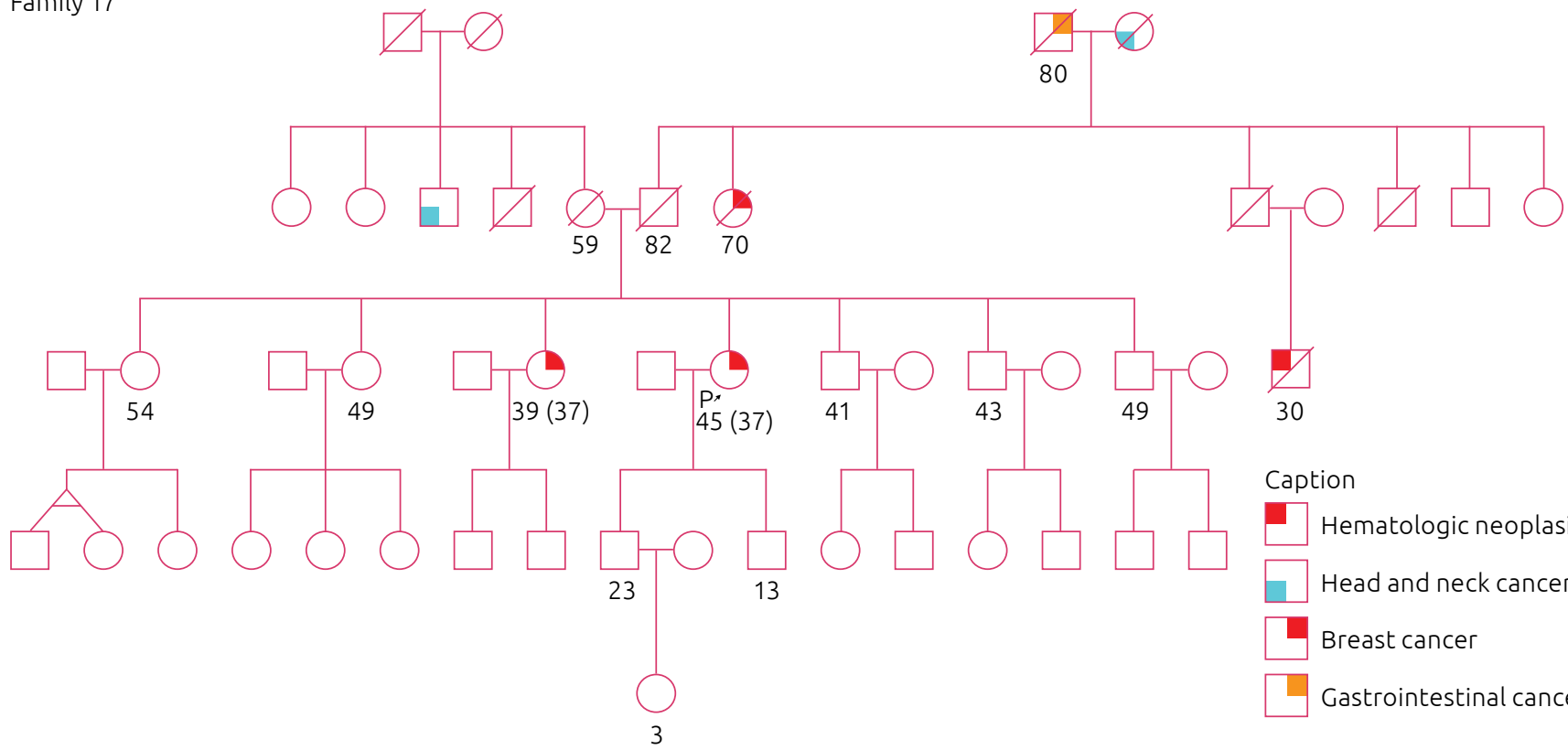

Family 18

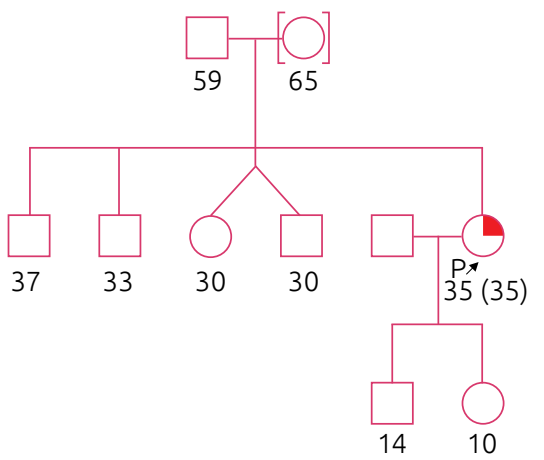

Caption

Breast cancer 
Family 19

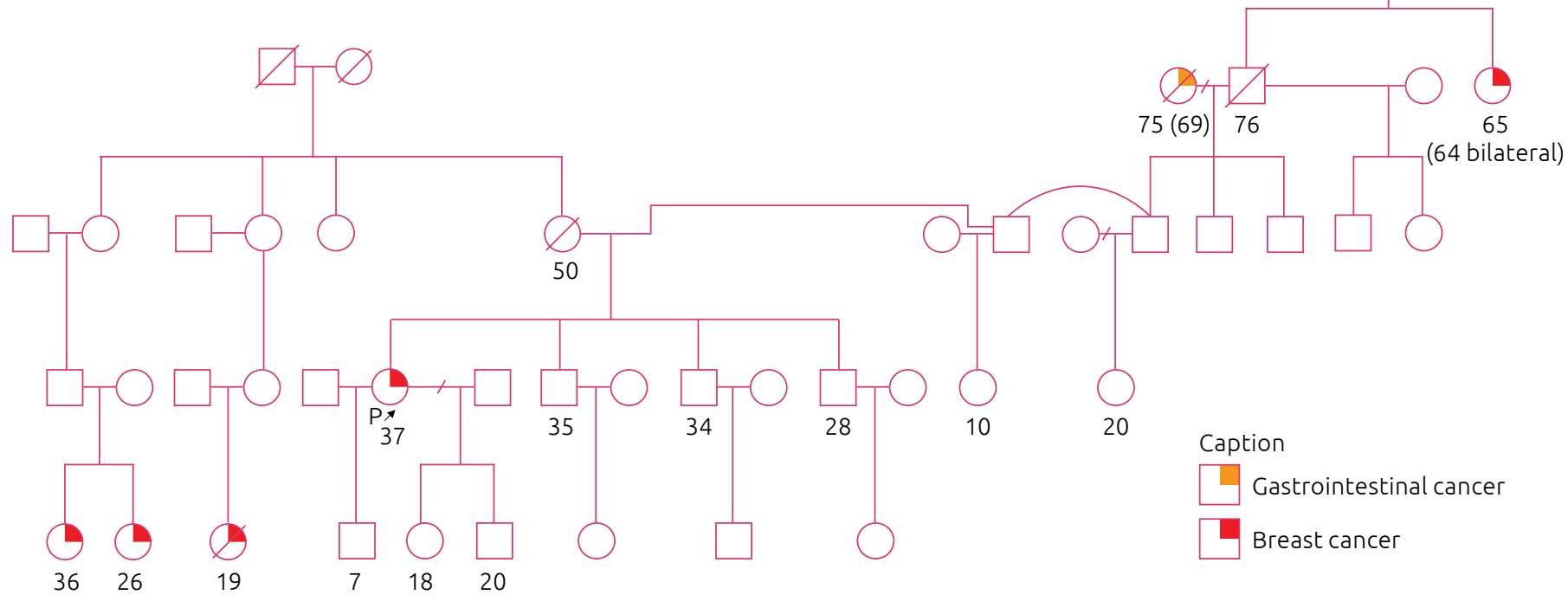

Family 20
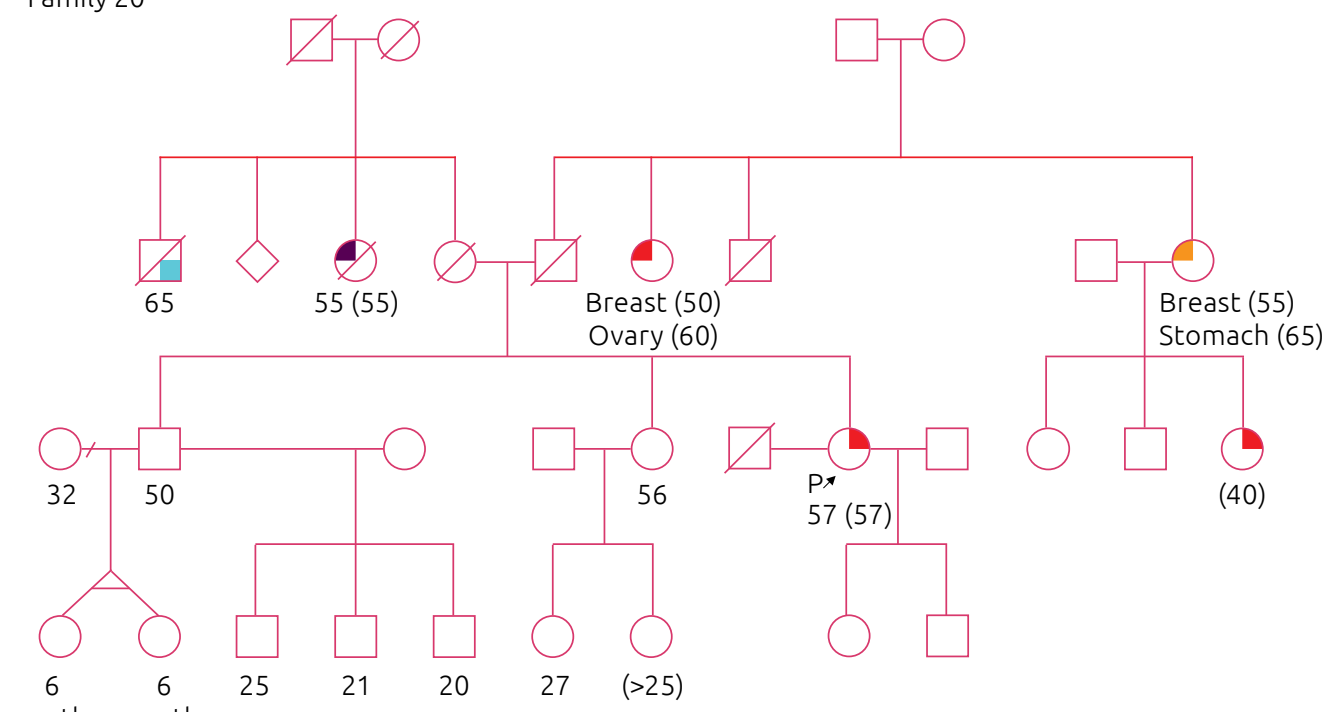

Caption

$\square$ Gastrointestinal cancer

- Cancer of the central

nervous system

Breast cancer

Bladder cancer

$\square$ Ovarian cancer

months months

Family 21

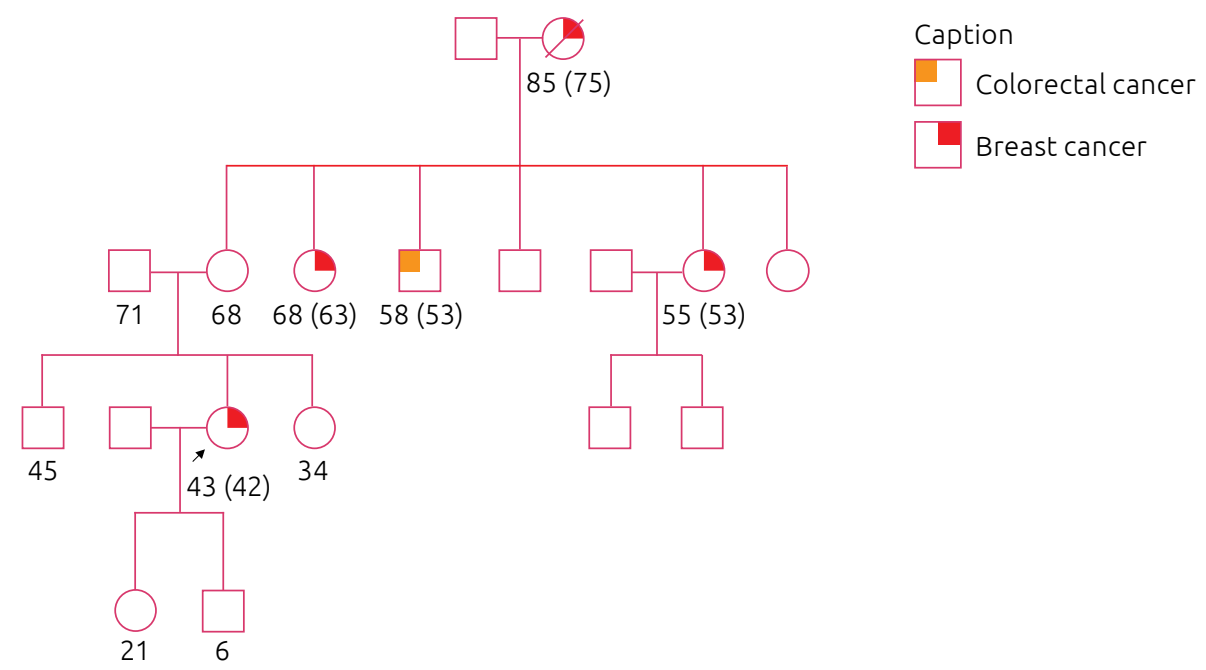




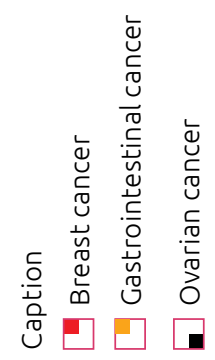

$\approx$

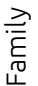

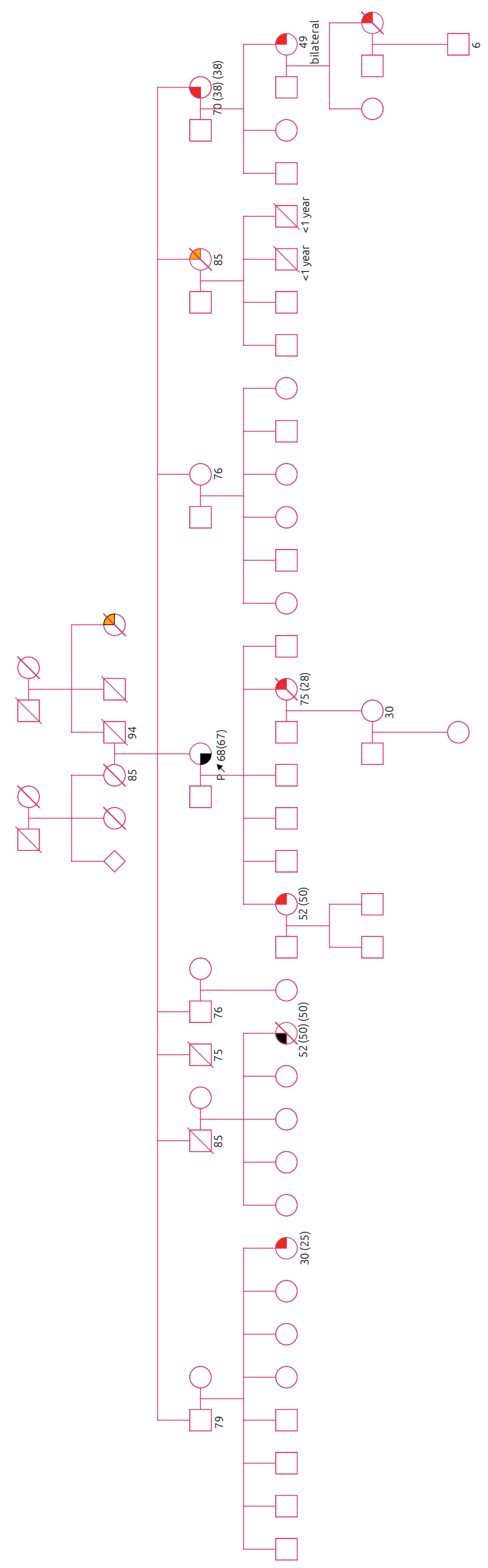


Family 23

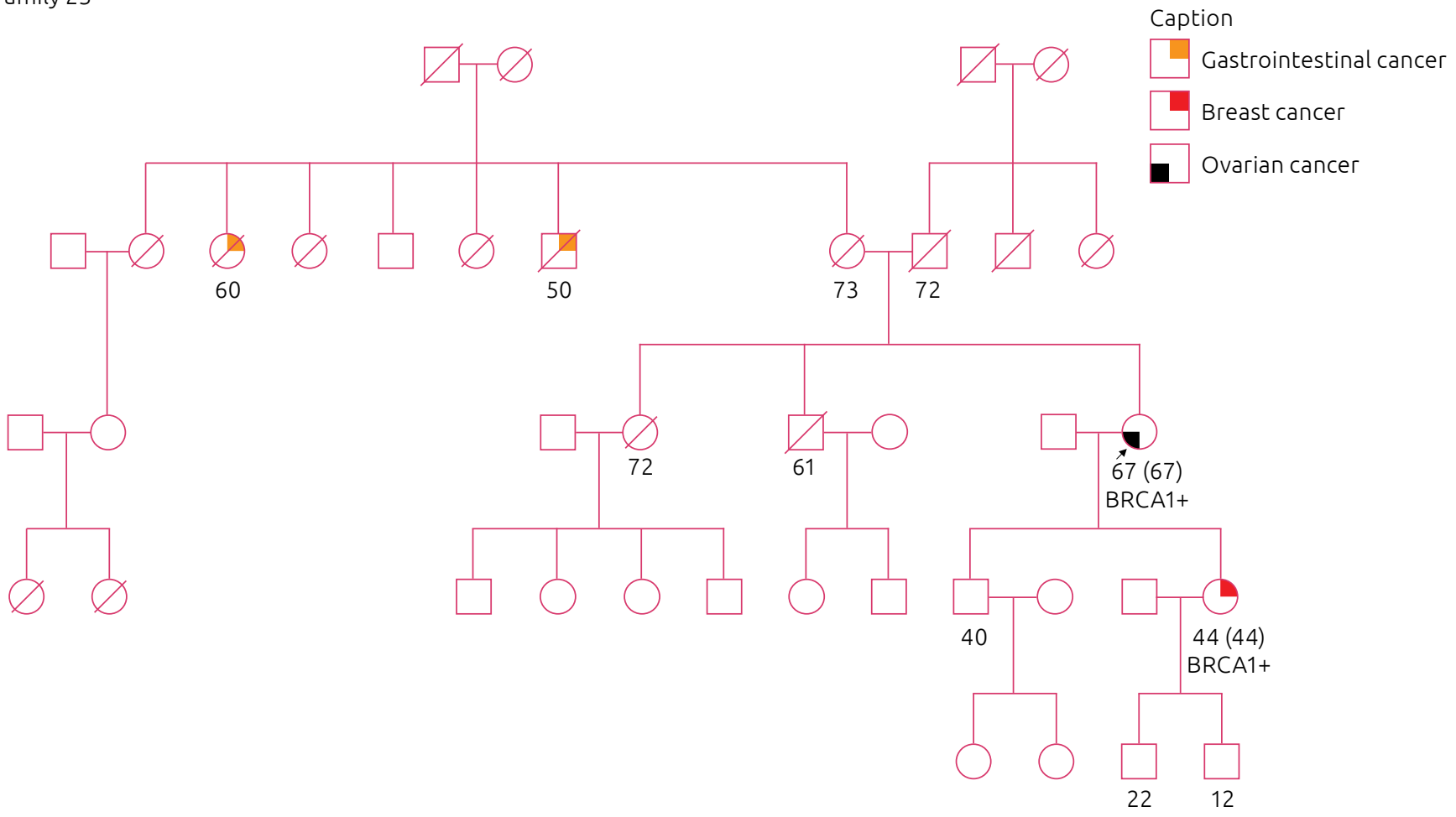

Family 25

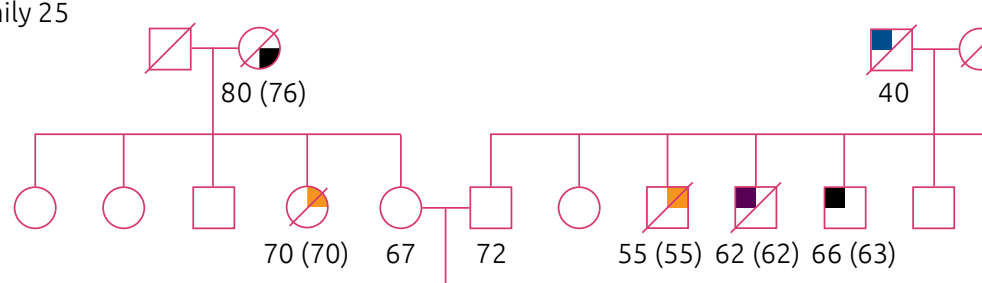

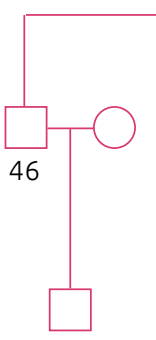

8
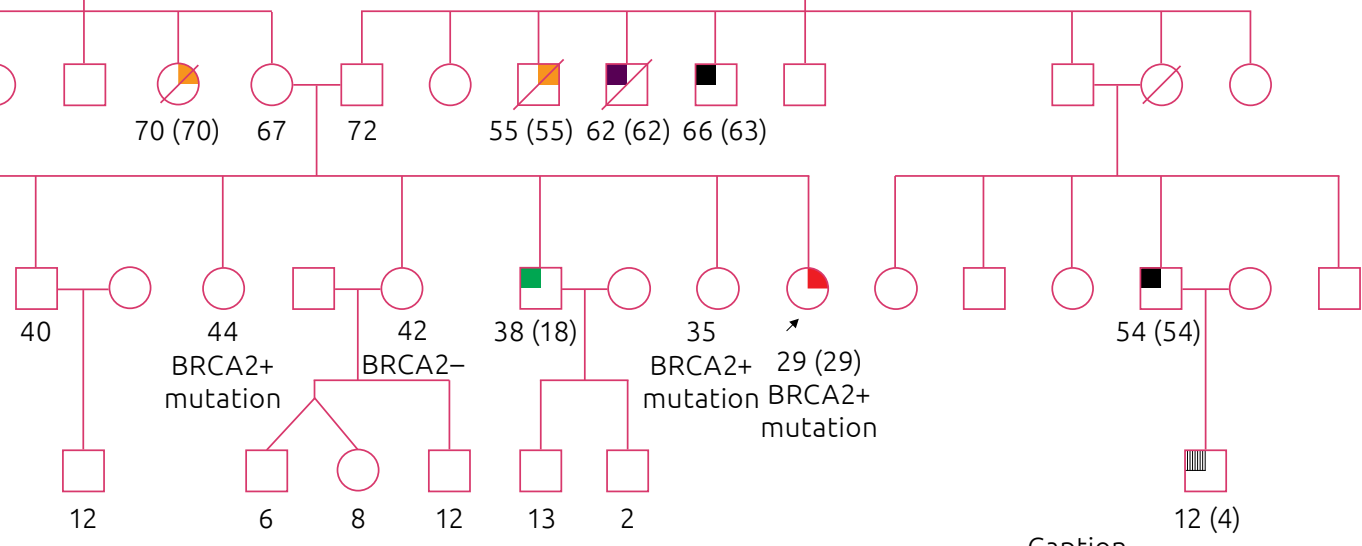

Caption

- Cancer of the central nervous system

Gastrointestinal cancer

- Cancer without site

Lung cancer

Breast cancer

- Hematologic neoplasia

- Prostate cancer

III Neuroblastoma 

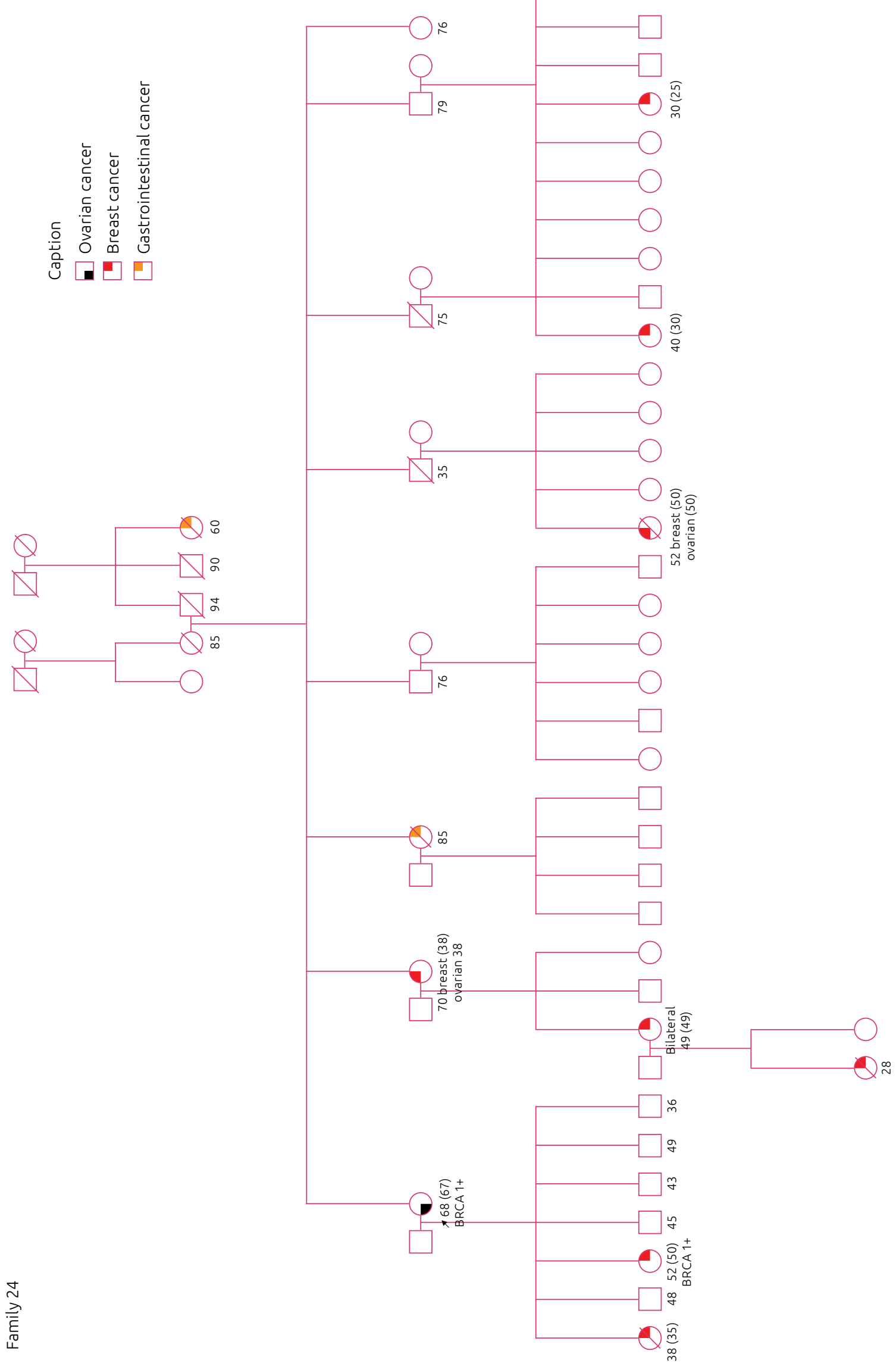